\title{
Influence of light-absorbing particles on snow spectral irradiance profiles
}

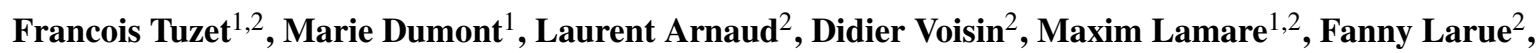 \\ Jesus Revuelto $^{1}$, and Ghislain Picard ${ }^{2}$ \\ ${ }^{1}$ Univ. Grenoble Alpes, Université de Toulouse, Météo France, CNRS, CNRM, Centre d'Étude de la Neige, Grenoble, France \\ ${ }^{2}$ UGA, CNRS, Institut des Geosciences de l'Environnement (IGE) UMR 5001, Grenoble, France
}

Correspondence: Francois Tuzet (francois.tuzet@meteo.fr)

Received: 18 March 2019 - Discussion started: 9 April 2019

Revised: 10 July 2019 - Accepted: 11 July 2019 - Published: 19 August 2019

\begin{abstract}
Light-absorbing particles (LAPs) such as black carbon or mineral dust are some of the main drivers of snow radiative transfer. Small amounts of LAPs significantly increase snowpack absorption in the visible wavelengths where ice absorption is particularly weak, impacting the surface energy budget of snow-covered areas. However, linking measurements of LAP concentration in snow to their actual radiative impact is a challenging issue which is not fully resolved. In the present paper, we point out a new method based on spectral irradiance profile (SIP) measurements which makes it possible to identify the radiative impact of LAPs on visible light extinction in homogeneous layers of the snowpack. From this impact on light extinction it is possible to infer LAP concentrations present in each layer using radiative transfer theory. This study relies on a unique dataset composed of 26 spectral irradiance profile measurements in the wavelength range $350-950 \mathrm{~nm}$ with concomitant profile measurements of snow physical properties and LAP concentrations, collected in the Alps over two snow seasons in winter and spring conditions. For 55 homogeneous snow layers identified in our dataset, the concentrations retrieved from SIP measurements are compared to chemical measurements of LAP concentrations. A good correlation is observed for measured concentrations higher than $5 \mathrm{ng} \mathrm{g}^{-1}\left(r^{2}=0.81\right)$ despite a clear positive bias. The potential causes of this bias are discussed, underlining a strong sensitivity of our method to LAP optical properties and to the relationship between snow microstructure and snow optical properties used in the theory. Additional uncertainties such as artefacts in the measurement technique for SIP and chemical contents along with LAP absorption efficiency may explain part of this bias. In addition, spectral information on LAP absorption can be retrieved from SIP measurements. We show that
\end{abstract}

for layers containing a unique absorber, this absorber can be identified in some cases (e.g. mineral dust vs. black carbon). We also observe an enhancement of light absorption between 350 and $650 \mathrm{~nm}$ in the presence of liquid water in the snowpack, which is discussed but not fully elucidated. A single SIP acquisition lasts approximately $1 \mathrm{~min}$ and is hence much faster than collecting a profile of chemical measurements. With the recent advances in modelling LAP-snow interactions, our method could become an attractive alternative to estimate vertical profiles of LAP concentrations in snow.

\section{Introduction}

Snow is a highly reflective medium in the wavelengths of the visible and of the near infrared (up to $1.4 \mu \mathrm{m}$, referred to as NIR) where most of the solar energy is available (Warren, 1982). The amount of solar energy absorbed by snow-covered areas is hence small compared to other surfaces such as bare soil, vegetation or oceans, making snow a singular component of our climate system (Armstrong and Brun, 2008). Snow optical properties depend on its physicochemical characteristics whose evolution is driven by atmospheric conditions (Colbeck, 1982; Aoki et al., 2006). This dependence involves snow in strong optical feedback loops that are of crucial importance for the snowpack evolution and are still poorly understood (Hall, 2004; Box et al., 2012). Light-absorbing particles (LAPs) in snow, such as mineral dust (referred to as dust in the following; Di Mauro et al., 2015), black carbon (BC; Painter et al., 2013) or algae (Cook et al., 2017), trigger and amplify these snow albedo feed- 
backs, impacting significantly the cryosphere and its evolution under a changing climate (Skiles et al., 2018).

Linking snow albedo to snow physical properties and LAP concentrations has been an active field of research over the last decades (e.g. Wiscombe and Warren, 1980; Hadley and Kirchstetter, 2012; Skiles, 2014; Adolph et al., 2017). Nowadays the underlying theory is well known (Warren, 1982), and many radiative transfer models are able to numerically compute snow optical properties for given physical properties and LAP concentrations (e.g. Flanner and Zender, 2006; Aoki et al., 2011; Tuzet et al., 2017). However, from a practical point of view, modelling the impact of LAPs on the optical properties of snow still remains challenging due to several issues. Firstly, chemical analyses of snow samples to determine concentrations and size distributions of LAPs are time consuming and suffer from intrinsic limitations, since most analytical techniques are only sensitive to certain particle sizes. In the case of $\mathrm{BC}$, where direct determinations which are only sensitive to small size particles coexist with filtration-based techniques mostly sensitive to larger size particles, Schwarz et al. $(2012,2013)$ estimate that the resulting uncertainties on total $\mathrm{BC}$ concentrations in snow can be as high as $60 \%$. Secondly, the radiative impact of a given concentration of LAPs is highly uncertain due to strong variations of the LAP intrinsic optical characteristics driven by their physical (e.g. size distribution, density, ageing) and chemical (e.g. coating, hygroscopicity) properties. Coating of LAPs by non-absorbing aerosols is, for example, suspected to enhance their absorption efficiency by up to a factor of 3 (e.g. Schnaiter et al., 2005; Moffet and Prather, 2009). Caponi et al. (2017) highlighted the high variability of the optical properties of dust particles with respect to their size distribution and their origin, leading to a 1-order-of-magnitude uncertainty in absorption by dust for a given mass. Thirdly, the interactions between LAPs and snow are known to impact LAP absorption efficiency but are still poorly understood. Flanner et al. (2012) highlighted that for a given BC concentration in snow, the absorption can be up to twice as much if particles are inside the ice rather than in the air surrounding the ice, but estimating LAP mixing state is challenging. Moreover, knowledge about the impact of LAP-snow interactions on other particle properties such as size distribution, coating or hygroscopicity is still at an early stage. Dong et al. (2018) recently revealed that more particles are coated by other species in snow and ice than in the atmosphere, but the impact on radiative transfer has not yet been evaluated. All these issues have been reported for years (e.g. Doherty et al., 2010; Flanner et al., 2012; He et al., 2017) and are still unsolved, mostly due to the difficulty in observing LAPs in snow with simultaneous measurements of their optical properties.

Determining LAP absorption in snow is a complex experimental problem which can be difficult to address with a direct approach such as joint measurements of chemical concentrations and albedo. Indeed, not only do chemical measurements present high uncertainties as mentioned above, but albedo measurements also have uncertainties of their own, hindering the detection of the effect of LAPs on albedo at low concentrations (Warren, 2013). Even at higher concentrations, the precise vertical distribution of the LAPs in the uppermost millimetres is crucial for an accurate estimation of albedo. However, sampling snow with such a high vertical resolution in snow pits is rarely achieved. Recent studies based on hyperspectral (e.g. Dal Farra et al., 2018) or TEM-EDX (e.g. Dong et al., 2018) microscopy bring an understanding of the physico-chemical properties of LAPs in snow at the particle scale but remain difficult to apply to a large number of samples. To date, the understanding of LAP absorption efficiency in snow remains strongly uncertain although it is a crucial parameter to accurately model their impact on the cryosphere.

In this study, we propose an alternative approach, based on spectral irradiance profile (SIP) measurements in snow, from which snow extinction can be retrieved and compared to the expected optical impact of LAPs. Even if most of the energy is absorbed in a very thin top layer (few millimetres; Brandt and Warren, 1993; Libois et al., 2013), understanding light penetration is of crucial importance for the thermal regime of the snowpack (Flanner and Zender, 2005; Picard et al., 2012), for photosynthetic activity of underlying vegetation (Richardson and Salisbury, 1977) and for in-snow photochemistry (Grannas et al., 2007; Domine et al., 2008; France et al., 2012). Light penetration and transmittance measurements in snow started with Liljequist (1956). Section D.3 in Warren (1982) summarises available measurements at that time. They were mostly limited to monochromatic or spectrally integrated radiation. More recently, spectrally resolved irradiance profiles have been measured in the UV and visible for photochemistry purposes (e.g. King et al., 2001; France et al., 2012). In addition to their SIP measurements, France et al. (2012) had concomitant chemical measurements of carbonaceous species (Voisin et al., 2012). They observed that measured LAP concentrations were too low to explain the absorption of the snowpack in the visible assuming state-ofthe-art LAP absorption efficiencies.

A few studies have undertaken comparisons between SIP measurements and radiative transfer theory. Libois et al. $(2013,2014)$ measured SIPs in the visible and NIR to determine the absorption enhancement factor related to the shape of the ice crystals in snow. Warren et al. (2006) and Picard et al. (2016) refined the absorption spectrum of pure ice by combining SIP measurements and radiative transfer theory relying on the absence of LAPs in Antarctic snow. Picard et al. (2016) suggested that BC traces as low as $5 \mathrm{ng} \mathrm{g}^{-1}$ have a detectable effect on SIP measurements, meaning that SIP measurements could be an order of magnitude more sensitive to LAPs than albedo measurements. It is consistent with the study of Reay et al. (2012) that highlighted that $\mathrm{OH}$ and $\mathrm{NO}_{2}$ production in depth is strongly impacted by small changes in LAP concentration in snow. Accounting for LAPs when modelling light penetration in snow is hence of the utmost 
importance even when concentrations are too low to significantly impact albedo.

This paper investigates the relationship between SIP measurements and chemically measured LAP concentrations in snow to assess the absorption efficiency of LAPs. To this end, 26 SIP measurements acquired in the French Alps are analysed using a radiative transfer model. LAP concentrations and snow physical properties explaining the spectral signature of SIP measurement are compared to in situ measurements. The uncertainties affecting the measurements and model parameters are also investigated.

Section 2 presents the measurement dataset consisting of combined measurements of SIPs, snow physical properties and chemical measurements profiles of $\mathrm{BC}$, and dust concentrations. Section 3 details the processing applied to the SIP measurements and the method used to compare them with radiative transfer modelling. Finally the results are presented in Sect. 4 and limitations of the method are discussed in Sect. 5.

\section{Data and study site}

Data were measured over $33 \mathrm{~d}$ during two winter seasons in 2016-2017 and 2017-2018 at the Col du Lautaret site $\left(45^{\circ} 02^{\prime} 28.7^{\prime \prime} \mathrm{N}, 6^{\circ} 24^{\prime} 38.0^{\prime \prime} \mathrm{E}\right)$ around $2100 \mathrm{~m}$ a.s.l. in the French Alps. This unique dataset includes SIP measurements with snow physico-chemical properties from a coincident snow pit. All the field sampling and measurements were performed by a single operator for the two seasons, ensuring a stable protocol, detailed in the following section. The dataset spans across a wide range of meteorological, illumination and snow conditions as the measurements were taken both in winter and spring conditions from the onset of the snow season to the total melt-out of the snowpack.

\subsection{Spectral irradiance profiles (SIPs)}

Up to three SIPs were collected each day on a flat, horizontal and unaltered snow surface using the SOLEXS (SOLar EXtinction in Snow; Libois et al., 2014) instrument, which consists of a fibre optic connected to a spectrometer. A full description and schematic illustrations of the instrument can be found in Libois et al. (2014) and in Sect. 2.1 of Picard et al. (2016).

First, a vertical hole of $10 \mathrm{~mm}$ diameter is drilled by inserting a metal rod up to a depth of $50 \mathrm{~cm}$ depending on the presence of hard layers in the snowpack. Second, the fibre optic, fitted in a white rod, is slowly inserted in this hole, taking precautions not to enlarge the hole. A few millimetres of snow was systematically added on the surface around the rod to shield the void space from direct sun beam in order to minimise the leak of additional solar radiation into the hole. The depth of the fibre is precisely measured with a magnetic coding ruler with $1 \mathrm{~mm}$ resolution. The fibre transmits light to a spectrophotometer operating in the spectral range
$300-1100 \mathrm{~nm}$ with $3 \mathrm{~nm}$ spectral resolution. A spectrum is acquired every $5 \mathrm{~mm}$ during descent and ascent, ensuring a $5 \mathrm{~mm}$ vertical resolution or better. An acquisition takes from 7 to $1000 \mathrm{~ms}$ depending on the overall irradiance, which is mainly a function of depth. In total a two-way profile is completed in about a minute, a period during which the incoming radiation can vary. A photosensor is placed at the surface to record variations of broadband incident irradiance in order to detect large variations and allow the correction of small variations.

The SIPs for which incident irradiance had varied more than $3 \%$ during the measurements were discarded. Spectral data at wavelengths less than $350 \mathrm{~nm}$ and more than $950 \mathrm{~nm}$ are usually very noisy and are not exploited here, because of the sharp decrease in the irradiance with wavelength in the NIR, associated with the low sensitivity of the spectrometer in that range, as well as the limited incoming radiation in the UV. When the operator begins the acquisition of the SIP, the magnetic ruler measurement is set to 0 in order to acquire depth from the top of the snowpack. For six profiles of the whole dataset, a vertical offset of a few millimetres was introduced in the SIP measurement during operation. By visualising the profiles, we applied an ad hoc correction by taking the first point where irradiance starts decreasing as $z=0$. In total, these six profiles were corrected by an offset smaller than $2 \mathrm{~cm}$.

\subsection{Snow pit data}

Vertical profiles of snow physical properties were collected at the exact position where the SIP was acquired. When multiple SIP acquisitions were performed on the same day, the physical properties were collected in between the different SIPs, which were never separated by more than $50 \mathrm{~cm}$. In the snow pit, density was measured at a $6 \mathrm{~cm}$ vertical resolution using a cylindric cutter with a volume of $0.5 \mathrm{~L}$. Ice layers were excluded for practical reasons. Following Proksch et al. (2016), who suggest an uncertainty on density measurements between $2 \%$ and $5 \%$, we consider a $5 \%$ relative uncertainty in our measurements. Specific surface area (SSA) vertical profiles were also collected. During the snow season 2016-2017, these profiles were measured with the DUFISSS instrument (DUal Frequency Integrating Sphere for Snow SSA measurement; Gallet et al., 2009), with one sample every $3 \mathrm{~cm}$, excluding ice layers. During the snow season 2017-2018, SSA profiles were measured with the ASSSAP instrument (Alpine Snowpack Specific Surface Area Profiler), which is a lightweight version of POSSSUM (Profiler Of Snow Specific Surface area Using SWIR reflectance Measurement; Arnaud et al., 2011). Over both seasons, measured SSA values range from 5 to $55 \mathrm{~m}^{2} \mathrm{~kg}^{-1}$. For this range of values, Gallet et al. (2009) and Arnaud et al. (2011) suggest that the DUFISSS and ASSSAP accuracy is around $10 \%$. It is noteworthy that Arnaud et al. (2011) also realised an inter-calibration of these two instruments and obtained a $6 \%$ 
rms difference. Concomitant measurements of temperature, wetness and snow grain type according to Fierz et al. (2009) were also performed in snow pits.

\subsection{Chemical analyses}

The vertical profiles of dust and refractory black carbon (rBC) concentration were measured with a $3 \mathrm{~cm}$ vertical resolution on the samples taken from the uppermost $20 \mathrm{~cm}$ of the snowpack at least. Snow was sampled in triplicates in sterile $50 \mathrm{~mL}$ polypropylene centrifugation tubes with extra care to avoid any contamination by the operator. The samples remained frozen until analysis, avoiding freeze-thaw cycles suspected to impact LAP size distribution in snow (e.g. Lim et al., 2014; Schwarz et al., 2013). In the laboratory, $\mathrm{BC}$ was analysed immediately after melting as $\mathrm{rBC}$, using a single particle soot photometer ( $\mathrm{SP}^{2}$, Droplet Measurement Technologies). Samples were nebulised and the resulting aerosol was analysed in the laboratory following the procedure described in Wendl et al. (2014). External calibration samples with freshly prepared Aquadag standards were run before each sample series. As the size distribution of the Aquadag samples was close to the size distribution of BC in snow, the nebulisation biases between standards and samples were minimised. Typical analytical repeatability and calibration uncertainties cumulate to $\sim 5 \%$, but this does not account for potential nebulisation biases due to dissimilarities between the size distributions of BC in snow and the standards. The nebuliser used in the analysis causes potential maximum biases up to $20 \%$. The maximum uncertainty of rBC measurements combining in quadrature nebulisation biases, calibration uncertainties and repeatability is estimated to $\sim 21 \%$.

Dust size distributions and concentrations were measured with a Coulter counter following Delmonte et al. (2004). The measured sizes span a range of 0.6 to $21 \mu \mathrm{m}$, in $256 \mathrm{log}$ arithmically spaced size bins. Coulter counter counts and measures insoluble particles, so we assume here that insoluble particles above $0.6 \mu \mathrm{m}$ are mainly dust particles, which agrees well with the measured volume weighted average size for our measurements (typically 1.2 to $4 \mu \mathrm{m}$ ). Depending on initial concentrations, samples were diluted by a factor of up to 100 and the blank concentration was subtracted. This correction stayed below $7 \%$ for three-fourths of the samples. The Coulter counter measurement total uncertainty for dust concentration is estimated to $\sim 10 \%$.

\section{Methods}

\subsection{LAP concentration}

Since several LAP types are present in the snowpack at any time over a season, it is convenient to present results in terms of effective optically equivalent $\mathrm{BC}$ (eqBC) concentrations $c_{\text {eqBC }}$ as in Dumont et al. (2017). For both measured and es- timated LAP concentrations, the eqBC concentration is calculated as

$c_{\mathrm{eqBC}}=c_{\mathrm{BC}}+\psi\left(c_{\mathrm{dust}}\right)$,

where $c_{\mathrm{BC}}$ is the $\mathrm{BC}$ concentration and $c_{\text {dust }}$ is the dust concentration. $\psi$ is a function computing the $\mathrm{BC}$ concentration that would have the same integrated radiative impact from 350 to $900 \mathrm{~nm}$ as the input dust concentration (Fig. 1b). To do so, the energy absorbed by a semi-infinite snowpack with a SSA of $15 \mathrm{~m}^{2} \mathrm{~kg}^{-1}$ is computed at each wavelength between 350 and $900 \mathrm{~nm}$. The spectral incoming irradiance is computed with the detailed atmospheric radiative model SBDART (Ricchiazzi et al., 1998), for mid-latitude winter in clear sky conditions. It is noteworthy that the function $\psi$ has a strong dependence on the spectral distribution of the incident solar radiation and on the radiative transfer model parameters, mainly on the selected values of $\mathrm{BC}$ and dust mass absorption efficiency (MAE). These MAE values are represented in Fig. 1a and detailed in Sect. 3.4.2. Strictly speaking, $\psi$ also depends on the BC concentration and on the SSA of the snowpack, but this minor impact is neglected here.

In the following, the LAP concentrations are expressed in $\mathrm{ng} \mathrm{g}^{-1}$ eqBC. Concerning the measurements, the concentration of a layer is computed as the mean of all concentration measurements in this layer, weighted by the measured density associated with this layer. As BC in our snow samples is analysed as $\mathrm{rBC}$, we use the abbreviation eqrBC for measurements. Using eqBC makes it possible to represent all LAP impacts with a single number, which is clearer but comes with assumptions that must be kept in mind for the interpretation.

Since different types of LAPs have different spectral signatures (Fig. 2), it is theoretically possible to assess the dominant type of LAPs using our SIP measurements. With this aim in mind, we compute the relative optical impacts of dust and $\mathrm{BC}$ within this eqBC concentration. The fraction of total LAP absorption caused by dust $(\eta)$ is computed as follows:

$\eta=\frac{\psi\left(c_{\mathrm{dust}}\right)}{c_{\mathrm{eqBC}}}$.

\subsection{Selection of homogeneous layers in SIP measurement}

Following the radiative transfer theory in a homogeneous layer far from any interface, the intensity at a given wavelength $\lambda, I(z, \lambda)$, decreases exponentially with depth. This is written as

$I(z, \lambda)=I\left(z_{0}, \lambda\right) \mathrm{e}^{-k_{\mathrm{e}}(\lambda)(z-z 0)}$,

where $k_{\mathrm{e}}(\lambda)$ is the asymptotic flux extinction coefficient (AFEC; $\mathrm{m}^{-1}$ ), $z$ is the depth increasing downwards and $z_{0}$ is a reference depth. Simpson et al. (2002) explain that this 

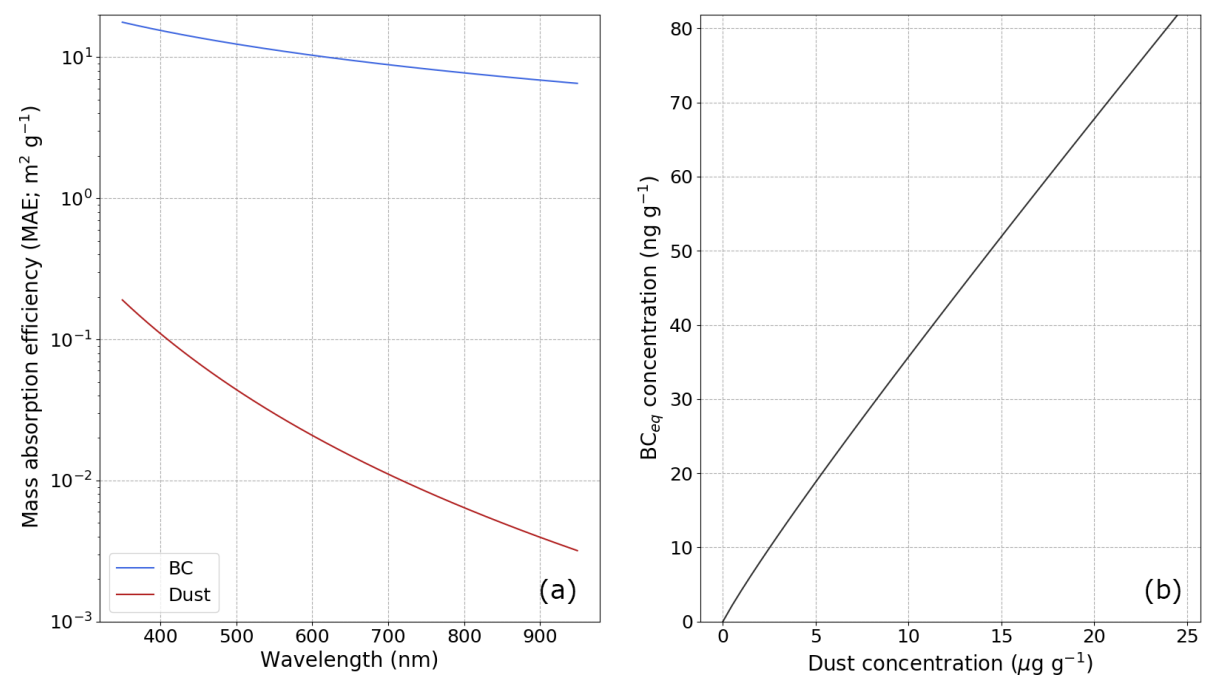

Figure 1. (a) Mass absorption efficiency (MAE) values of BC and dust used in the present study as a function of wavelength. (b) The eqBC concentration corresponding to a given dust concentration using these MAE values and the methods described in Sect. 3.1.

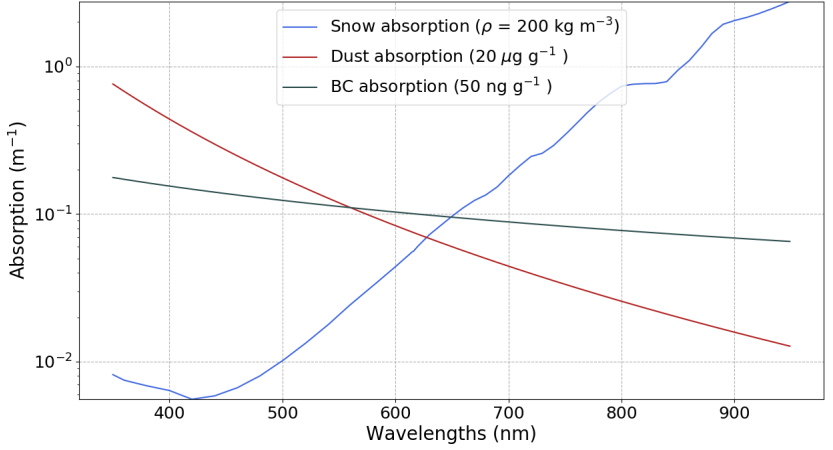

Figure 2. Spectral signature of the absorption coefficients $\sigma_{\mathrm{a}}$ for snow and different types of LAPs assuming a snow density of $200 \mathrm{~kg} \mathrm{~m}^{-3}$.

equation is only applicable in the asymptotic region, the region where light is only diffuse and where the ground absorption has no influence. For this reason the uppermost $7 \mathrm{~cm}$ of the snowpack and the profiles acquired in shallow snowpacks (less than $50 \mathrm{~cm}$ ) are discarded from our analysis. Note that the minimum distance between the ZOI and the ground is $18 \mathrm{~cm}$, which we believe is thick enough to prevent any significant disturbance of the measured signal due to the presence of the ground.

For a homogeneous layer in the asymptotic region, the AFEC can hence be computed as the gradient of the logradiance (logarithm of the irradiance) in the layer. However, Picard et al. (2016) have shown that the rod of SOLEXS can disturb the gradient of the log-radiance in the first centimetres around a transition between two layers of different scattering properties. For this reason, only homogeneous layers of the snowpack thicker than $3 \mathrm{~cm}$ can be exploited. Following the approach of Warren et al. (2006) and Picard et al.
(2016), we visually determine zones having homogeneous properties based on the linearity of the log-radiance in the asymptotic region. We refer to those vertical layers with homogeneous properties as zones of interest (ZOIs). In total, we identified 100 ZOIs over the 26 SIPs measured over both seasons. Figure 3a shows an example of selected ZOIs.

\subsection{Asymptotic flux extinction coefficient estimation}

For every ZOI, we estimate the AFEC with a least-squares linear regression of the log-radiance versus depth, based on Eq. (3). To deal with the spectrometer noise for wavelengths where the signal is the weakest, the procedure to compute the AFEC for a specific ZOI is as follows:

1. For a given wavelength $\lambda$, if any $I(z, \lambda) \leqslant 0$, the AFEC is not computed.

2. The AFEC is computed for all remaining wavelengths as a linear regression of the log-radiance. Nevertheless the computed AFEC is often affected by SIP measurement noise for the largest wavelengths. To address this issue, the AFEC is decomposed into signal and noise. The signal is calculated by applying a convolution filter with a period of $11 \mathrm{~nm}$ on the raw estimate, and the noise is calculated as the difference between the raw AFEC and the filtered one.

3. The signal-to-noise ratio of the AFEC is estimated as the ratio between the average signal and the average noise over a window of $30 \mathrm{~nm}$ at the higher range of the spectrum. If this ratio is lower than 15, the AFEC in this range is discarded. If the signal-to-noise ratio is still lower than 15 in the next $30 \mathrm{~nm}$, the last step is repeated. It should be noted that the signal-to-noise ratio is 

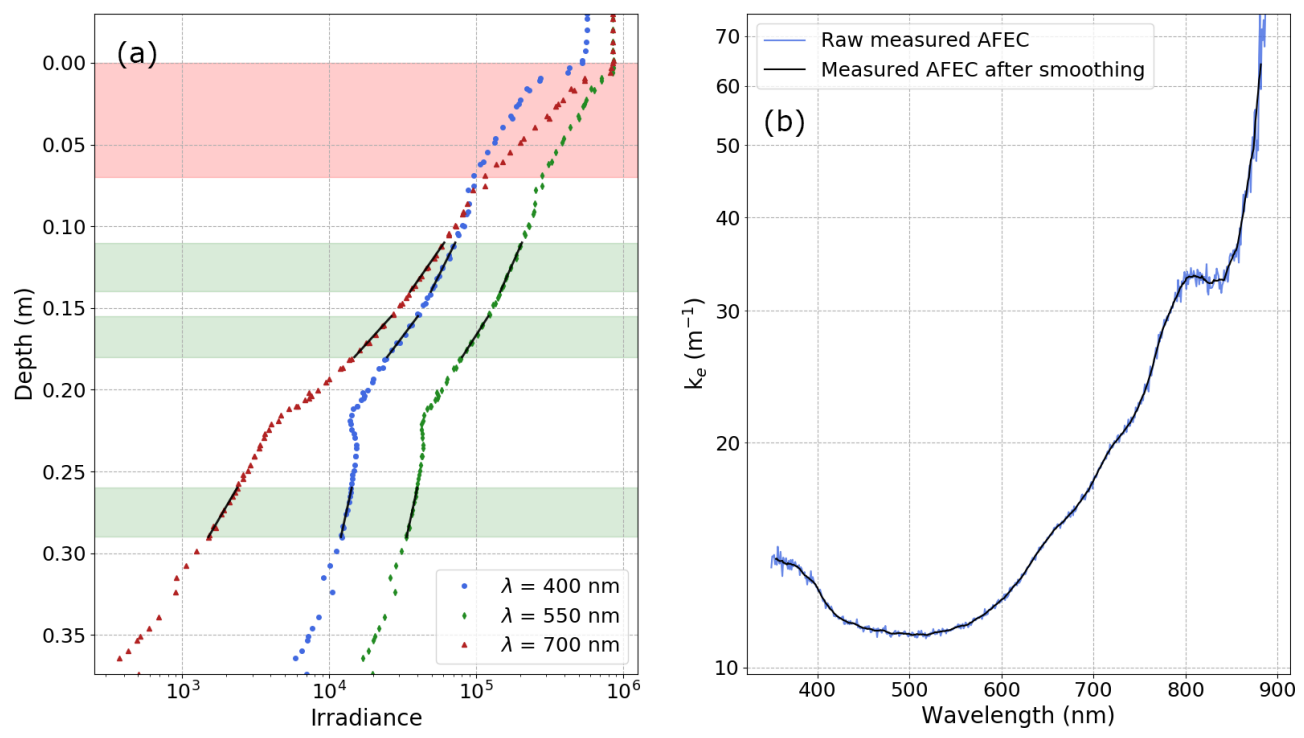

Figure 3. (a) Irradiance as function of depth for selected wavelengths for SOLEXS profile 002 on 13 February 2018. Green shading shows the zones of interest (ZOIs), which are homogeneous layers where the decrease in irradiance is visually linear on a logarithmic scale. The red shading corresponds to the part of the snowpack discarded due to the potential influence of direct light. (b) Measured AFEC (blue curve) and filtered AFEC (black curve) as a function of wavelength. Note that the ordinate scale is logarithmic.

constantly higher than 15 at the lower range of the spectrum, i.e. around $350 \mathrm{~nm}$. Figure 4 shows the selected maximum wavelength as a function of the bottom depth of the ZOI. Overall, the computation window varies between [350-680] nm and [350-944] nm with in general wider ranges at shallower depths. The maximum wavelength decreases with depth since the absorption of ice increases with wavelength. The relation is not deterministic because the available energy at a given depth also depends on the illumination conditions and on snow properties at the time of the measurement.

Figure $3 \mathrm{~b}$ shows an instance of the spectral AFEC computation obtained for a ZOI before and after applying the convolution filter. For more clarity, the AFEC estimated from SIP measurements will be referred as "measured AFEC" in the following.

\subsection{LAP retrieval algorithm}

\subsubsection{Theory}

The spectral AFEC $\left(k_{\mathrm{e}}(\lambda)\right)$ is related to snow single scattering properties (Wiscombe and Warren, 1980). Following Libois et al. (2013), under the delta-Eddington approximation (Joseph et al., 1976), for media and wavelengths where scattering is much stronger than absorption, the AFEC can be expressed as

$k_{\mathrm{e}}(\lambda) \approx \sigma_{\mathrm{e}} \sqrt{3(1-g \omega(\lambda))(1-\omega(\lambda))}$,

where $\sigma_{\mathrm{e}}\left(\mathrm{m}^{-1}\right), g$ and $\omega$ are the extinction coefficient, the asymmetry factor and the single scattering albedo respec-

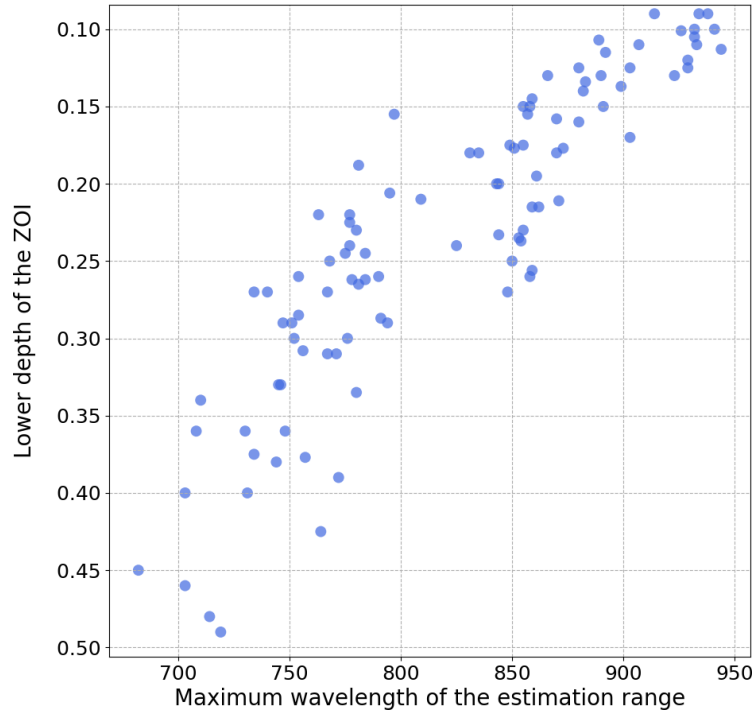

Figure 4. Upper limit of the spectral range where the AFEC estimation shows a signal-to-noise ratio over 15 for the whole dataset (100 ZOIs).

tively. This equation applies, among others, to snow in the wavelength range targeted by this study $(350-950 \mathrm{~nm})$ where snow is strongly scattering. The asymptotic approximation of the radiative transfer theory (AART; Kokhanovsky and Zege, 2004) for pure snow shows that for convex crystals

$\sigma_{\mathrm{e}}=\frac{\rho \mathrm{SSA}}{2}$ 
where $\rho$ is the density of snow and SSA is its specific surface area $\left(\mathrm{m}^{2} \mathrm{~kg}^{-1}\right.$; Legagneux et al., 2002). It can be expressed as SSA $=\frac{S}{\rho_{\text {ice } V}}$, where $S$ is the ice matrix surface area $\left(\mathrm{m}^{2}\right)$ of a given volume of ice $\left(V ; \mathrm{m}^{3}\right)$ and $\rho_{\text {ice }}$ is the density of ice equal to $917 \mathrm{~kg} \mathrm{~m}^{-3}$.

This theory also shows that

$\sigma_{\mathrm{a}}=\frac{\rho B \gamma_{\text {ice }}(\lambda)}{\rho_{\text {ice }}}$,

with $\sigma_{\mathrm{a}}\left(\mathrm{m}^{-1}\right)$ the absorption coefficient of snow due to ice and $B$ the absorption enhancement parameter. The term $\gamma(\lambda)$ $\left(\mathrm{m}^{-1}\right)$ is the absorption coefficient of bulk ice and is related to the imaginary part of ice refractive index $n_{\mathrm{i}}(\lambda)$ as follows:

$\gamma_{\text {ice }}(\lambda)=\frac{4 \pi n_{\mathrm{i}}(\lambda)}{\lambda}$.

It follows that

$(1-\omega)(\lambda)=\frac{\sigma_{\mathrm{a}}}{\sigma_{\mathrm{e}}}=\frac{2 B \gamma_{\text {ice }}(\lambda)}{\rho_{\text {ice }} \mathrm{SSA}}$,

where $\rho$ is the snow density $\left(\mathrm{kg} \mathrm{m}^{-3}\right)$. In the case of snow containing LAPs, assuming that scattering is only due to the ice-air interfaces (Libois et al., 2013), Eq. (8) can thus be written as

$(1-\omega)(\lambda)=\frac{\sigma_{\mathrm{a}}+\sigma_{\mathrm{a}, \mathrm{LAP}}}{\sigma_{\mathrm{e}}}$,

with $\sigma_{\mathrm{a}}$, LAP the absorption coefficients due to LAPs. Assuming external mixing, $\sigma_{\mathrm{a}, \mathrm{LAP}}$ is expressed as

$\sigma_{\mathrm{a}, \operatorname{LAP}}=\sum_{\mathrm{i}} \operatorname{MAE}_{\mathrm{i}}(\lambda) \rho_{\mathrm{i}}=\rho \sum_{\mathrm{i}} M A E_{\mathrm{i}}(\lambda) c_{\mathrm{i}}$,

where $i$ runs over the different types of LAPs present in snow. For each LAP type $i, \mathrm{MAE}_{\mathrm{i}}$ is the mass absorption efficiency $\left(\mathrm{m}^{2} \mathrm{~kg}^{-1}\right.$; e.g. Caponi et al., 2017), $\rho_{\mathrm{i}}$ is the mass concentration $\left(\mathrm{kg} \mathrm{m}^{-3}\right)$ and $c_{\mathrm{i}}$ the mass fraction $\left(\mathrm{kg} \mathrm{kg}^{-1}\right)$. Equation (9) yields

$(1-\omega)(\lambda)=\frac{2}{\operatorname{SSA}}\left(\frac{B \gamma_{\text {ice }}(\lambda)}{\rho_{\text {ice }}}+\sum_{\mathrm{i}} \operatorname{MAE}_{\mathrm{i}}(\lambda) c_{\mathrm{i}}\right)$

and finally

$k_{\mathrm{e}}(\lambda) \approx \sqrt{\frac{3(1-g)}{2} \rho^{2} \operatorname{SSA}\left(\frac{B \gamma_{\mathrm{ice}}(\lambda)}{\rho_{\text {ice }}}+\sum_{\mathrm{i}} \operatorname{MAE}_{\mathrm{i}}(\lambda) c_{\mathrm{i}}\right)}$.

The interesting feature of this equation is that the spectral dependence of the AFEC comes only from two terms, $\gamma_{\text {ice }}(\lambda)$ and $\operatorname{MAE}_{\mathrm{i}}(\lambda)$ of the different types of LAPs. Figure 2 represents the spectral dependence of $\sigma_{\mathrm{a} \text {, snow }}, \sigma_{\mathrm{a} \text {, dust }}$ and $\sigma_{\mathrm{a}, \mathrm{BC}}$. As their three spectral signatures are remarkably different in the visible range, it is theoretically possible to separate the absorption due to ice and that due to each type of LAP.

\subsubsection{Algorithm}

In order to exploit Eq. (12) to retrieve LAP concentrations from measured AFEC, several assumptions have to be made.

- The imaginary part of the refractive index of ice is known and is taken from the most recent estimate (Picard et al., 2016).

- The types of LAPs present in the snowpack are known. Here we assume two types: $\mathrm{BC}$ and dust without distinction within these categories.

- The mass absorption efficiency (MAE) of these LAPs is known.

- For BC it is derived from the constant BC refractive index advised by Bond and Bergstrom (2006), i.e. $m=1.91-0.79 i$. As in the study of Hadley and Kirchstetter (2012), BC density is scaled to obtain a MAE of $11.25 \mathrm{~m}^{2} \mathrm{~g}^{-1}$ at $550 \mathrm{~nm}\left(11 \mathrm{~m}^{2} \mathrm{~g}^{-1}\right.$ in their study), which is an intermediate value between fresh BC (around $7.5 \mathrm{~m}^{2} \mathrm{~g}^{-1}$ at $550 \mathrm{~nm}$ ) and internally mixed aged $\mathrm{BC}$ (up to $15 \mathrm{~m}^{2} \mathrm{~g}^{-1}$ at $550 \mathrm{~nm})$.

- One of the prevailing dust source regions for the Alps is the Saharan desert (Di Mauro et al., 2019). Consequently, the MAE of dust was set according to the values found in Caponi et al. (2017) for Libyan dust. The value advised for particles with a diameter smaller than $2.5 \mu \mathrm{m}\left(\mathrm{PM}_{2.5}\right)$ was chosen consistently with our chemical size distribution measurements.

- The snow shape parameters $B$ and $g$ are constant over time and for all types of snow. These parameters have a small dependence on the wavelength $\lambda$ implemented following Kokhanovsky (2004) and Appendix F of Libois (2014). This dependence is a function of the real part of ice refractive index $r_{i}$ which is taken from Warren and Brandt (2008) and is written as follows:

$$
\begin{aligned}
& B(\lambda)=B_{0}+0.4\left(r_{i}(\lambda)-1.3\right), \\
& g(\lambda)=g_{0}-0.38\left(r_{i}(\lambda)-1.3\right) .
\end{aligned}
$$

The absorption enhancement parameter $B_{0}$ is set to 1.6 and the asymmetry factor $g_{0}$ is set to 0.85 , which are considered to be good approximations to describe all types of snow (Libois et al., 2014). As the spectral dependence of $B(\lambda)$ and $g(\lambda)$ is small over the range of wavelengths targeted by this study, they are referred to as $B$ and $g$ for sake of simplicity.

Under these assumptions, the unknowns of the retrieval problem are $\mathrm{BC}$ concentration $\left(c_{\mathrm{BC}}\right)$, dust concentration $\left(c_{\text {dust }}\right)$ and $\rho^{2}$ SSA. As $\rho^{2}$ SSA is not an intuitive measure, we inject the measured density in Eq. (12) so that our third 
unknown becomes SSA. However, other choices are equally possible without any interference in the LAP retrievals. For instance, leaving both density and SSA as free parameters would not impact the LAP retrievals. For each ZOI, once the measured AFEC has been computed (Sect. 3.3), a nonlinear optimisation on SSA, $c_{\mathrm{BC}}$ and $c_{\text {dust }}$ in Eq. (12) is then performed to minimise the mean square error over all valid wavelengths between the estimated and the measured AFEC. The optimal parameters of this minimisation are our best estimates of $c_{\mathrm{BC}}, c_{\mathrm{dust}}$ and SSA. Figure 5 shows an example of comparisons between the estimated and measured AFEC for a specific ZOI.

In some rare cases, the estimated AFEC does not fit well with the measured one, resulting in a RMSE between the estimated and the filtered measured AFEC higher than $3 \mathrm{~m}^{-1}$. In these cases, the ZOI is discarded (5 out of 100). Since the theory described above does not account for the presence of liquid water, $16 \mathrm{ZOIs}$ containing liquid water are discarded, as we found this has a great influence on SIP measurements that is not yet understood. For the 79 remaining ZOIs, 55 have concomitant chemical measurements. Figure 6 shows the comparison between the retrieval algorithm on a specific SIP measurement and the corresponding snow pit measurements for a given field day.

In order to test the sensitivity of the method to the different modelling assumptions, numerical sensitivity analyses were performed. The impact on LAP estimation is calculated by varying each parameter within its range of uncertainty, keeping the other parameters unchanged. The impact of the different modelling assumptions is discussed in Sect. 4.2 and 4.3.

A scheme synthesising the whole methodology found in this section is presented in Fig. 7.

\section{Results}

\subsection{LAP estimation with optimal parameters}

Figure 8 compares the LAP concentrations estimated from the SIP measurements to the snow pit chemical measurements under the assumptions detailed in Sect. 3.4.2. The symbols correspond to the $55 \mathrm{ZOIs}$ for which corresponding chemical measurements are available. The horizontal error bars correspond to the measurement uncertainties described in Sect. 2. The colour of the symbols indicates the contribution of dust to the total LAP impact according to chemical measurements ( $\eta_{\text {mes }}$ from Eq. 2). The size of the symbols corresponds to the span of wavelengths used for the estimation - in other words the size of the symbols increases with the maximum wavelength on which the retrieval algorithm is applied. Neither the wavelength range used for the retrieval estimation nor the value of $\eta_{\text {mes }}$ is found to be correlated with the accuracy of the retrieval.

This figure has two important implications; first, the retrieval method is not sensitive to LAP amounts lower than
$5 \mathrm{ng} \mathrm{g}^{-1}$ eqBC, which may seem disappointing because it greatly reduces the number of validation points; nevertheless it was expected that the algorithm has a limit of sensitivity. The value of $5 \mathrm{ng} \mathrm{g}^{-1}$ is in line with the observations of Picard et al. (2016) in Antarctica. For this reason all the points with a measured eqrBC concentration lower than $5 \mathrm{ng} \mathrm{g}^{-1}$ are discarded from the statistics presented in the following. Second, the algorithm shows a sensitivity in the range 5$60 \mathrm{ng} \mathrm{g}^{-1}$. Indeed, the correlation in this range has an $r^{2}$ of 0.81 in spite of a significant bias of $14.6 \mathrm{ng} \mathrm{g}^{-1} \mathrm{eqBC}$, with the chemically measured concentrations being lower than the SOLEXS retrieval. The main purpose of the following is thus to investigate the cause of this bias by focusing on the snow layers with sufficient LAPs to be detected.

\subsection{Impact of LAP properties}

Figure 9 shows how the algorithm is impacted by uncertainties on LAP optical properties. The symbols are the same as in Fig. 8 with additional vertical error bars corresponding to the retrieval uncertainties caused by uncertainties on LAP MAE. The uncertainty on BC MAE is considered to be bounded by the two extreme values found in Hadley and Kirchstetter (2012) (7.5 and $15 \mathrm{~m}^{2} \mathrm{~g}^{-1}$ at $550 \mathrm{~nm}$ ). This uncertainty induces a $-26.6 \%,+46.6 \%$ uncertainty on our $\mathrm{BC}$ estimation, shown by the vertical bars in Fig. 9a. Figure $9 \mathrm{~b}$ shows the impact of dust MAE, considered as follows. Caponi et al. (2017) suggest that for dust particles smaller than $2.5 \mu \mathrm{m}\left(\mathrm{PM}_{2.5}\right)$, which is the major dust type in regard to measured size distribution, dust MAE at $407 \mathrm{~nm}$ is between 0.071 and $0.127 \mathrm{~m}^{2} \mathrm{~g}^{-1}$ (0.103 for Fig. 8) for north Saharan dust. The variations of dust MAE are assumed to span this range, inducing an asymmetric uncertainty of $-19 \%$, $+45.1 \%$ on dust estimation. The impact of changes in the spectral signature of dust absorption is not included here but is discussed in Sect. 5.3. It should be noted that higher values of dust MAE can be found in the literature and in turn higher uncertainties associated with this parameter could be considered. However, these values correspond to source regions that less likely affect our study area (e.g. up to $0.6 \mathrm{~m}^{2} \mathrm{~g}^{-1}$ in the Sahel desert, Caponi et al., 2017).

\subsection{Impact of snow physical parameters}

Both density and SSA were measured in the field. These measurements are not necessary to apply our LAP retrieval algorithm, but it is interesting to check if the SSA leading to the correct absorption is consistent with the measured SSA. Figure 10 shows the estimated SSA compared to the measured SSA for the 68 ZOIs previously selected for which SSA measurements are available. The horizontal error bars correspond to uncertainties on SSA measurements described in Sect. 2. Following Eq. (12) the AFEC is proportional to $\sqrt{\rho^{2} \mathrm{SSA}}$. For a given AFEC, the $5 \%$ uncertainty on density measurements thus introduces an asymmetric uncertainty of 


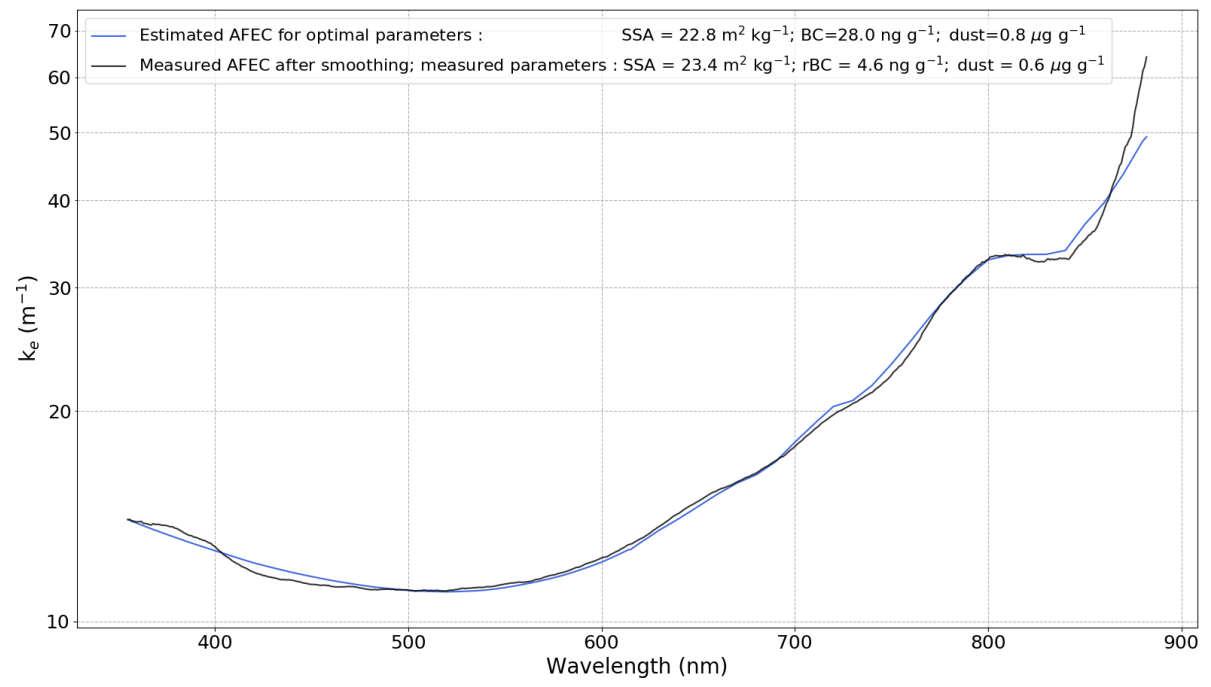

Figure 5. AFEC as a function of wavelength for the ZOIs between 11 and $14 \mathrm{~cm}$ on the SOLEXS profile 002 on 13 February 2018 . Measured AFEC after convolution filtering (black curve) is compared to the estimated AFEC from Eq. (12) with optimal parameters (blue curve). Note that $\mathrm{rBC}$ is the measured refractory $\mathrm{BC}$ concentration by the $\mathrm{SP}^{2}$ instrument.
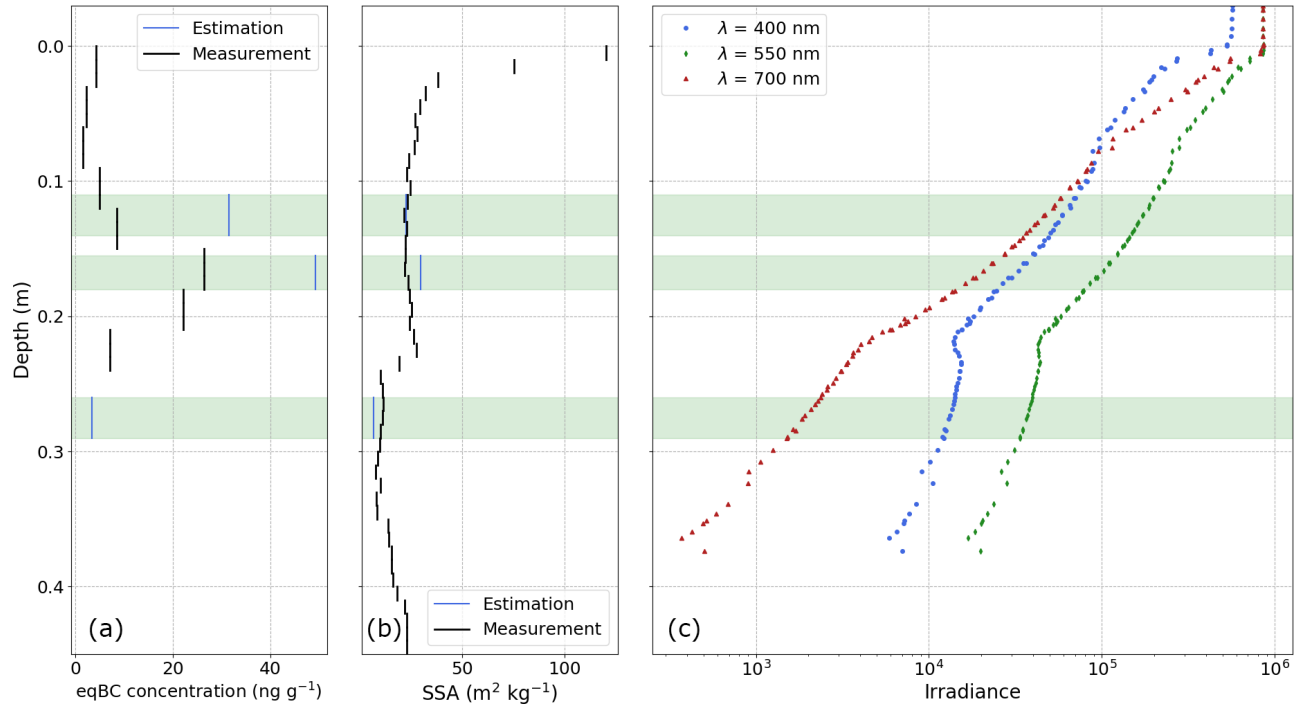

Figure 6. Comparison between snow pit measurements and estimated SSA and LAP concentrations for the SOLEXS profile 002 on 13 February 2018; green shading corresponds to the different ZOIs of the profile. (a) Vertical profile of eqBC concentration, measured (black) and estimated from AFEC optimisation on each ZOI (blue). (b) Vertical profiles of SSA, measured (black) and estimated from AFEC optimisation on each ZOI (blue). (c) SIP measurement from which AFEC has been derived.

$-9.1 \%,+11.1 \%$ on SSA estimation (vertical error bars). There is a correlation between estimated and measured SSA with an $r^{2}$ of 0.71 and no significant bias indicating that SSA variations are well captured by our retrieval algorithm. This result indicates that our LAP retrieval algorithm coupled with density profile measurements can also bring a relatively accurate estimation of SSA.

The SSA measurements are obtained from NIR reflectance based on the hypothesis that the shape parameters $B$ and $g$, from Eq. (12), are related by $\frac{B}{1-g}=10.7$. This value is considered to be good approximation to describe all types of snow (Gallet et al., 2009; Arnaud et al., 2011; Libois et al., 2014). However, the enhancement parameter $B$ and the asymmetry factor $g$ are expected to vary during snow metamorphism (Libois et al., 2013; Kokhanovsky and Zege, 2004), but their evolution is poorly documented. Libois et al. (2013) quantified the theoretical variations of $B$ and $g$ for different geometric shapes highlighting a high variability of these parameters. Under the constraint $\frac{B}{1-g}=10.7, B$ and $g$ can still vary according to grain shape, leading to potential 


\section{Field measurements}

Irradiance profile measurements

Selection of homogeneous layers

(Section 3.2)

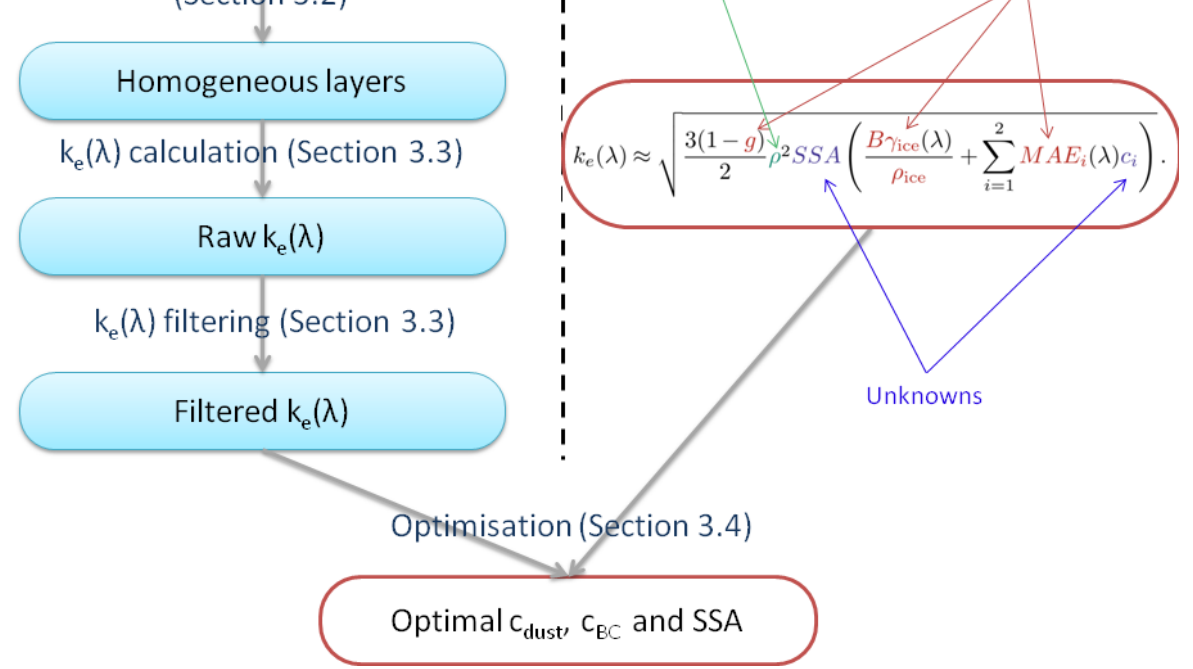

\section{Radiative transfer theory} for homogemeous layers

Section 3.4 : Equation 12

Measured values Prescribed values

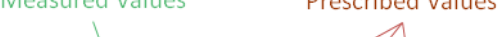

Figure 7. Scheme synthesising the principle of the LAP retrieval method presented in Sect. 3.

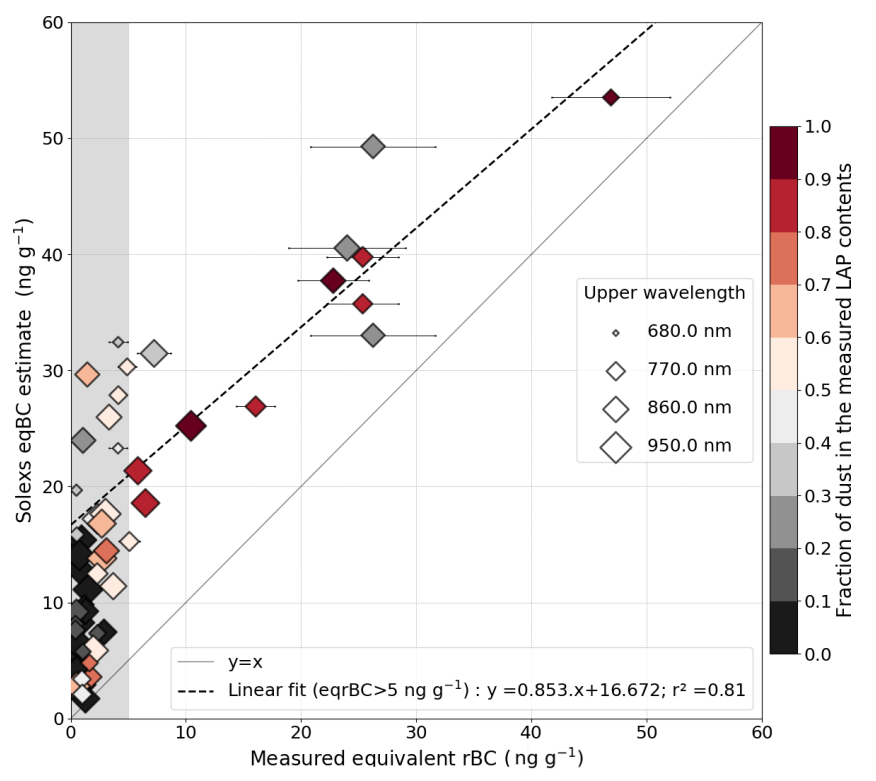

Figure 8. Comparison between measured and estimated eqBC concentrations for all the ZOIs with concomitant LAP measurements. The grey shading corresponds to the zone below the sensitivity limit of our method (i.e. $5 \mathrm{ng} \mathrm{g}^{-1}$ ). The linear fit in the dotted black line is computed for points where eqrBC measured concentration is higher than $5 \mathrm{ng} \mathrm{g}^{-1}$. The colour of the symbols corresponds to the proportion of LAP absorption coming from dust, and their size is related to the upper wavelength of the AFEC estimation. variations of $B(1-g)$ affecting our retrieval method. To account for these variations we selected extreme $B$ and $g$ values regarding this constraint based on Fig. 1 in Libois et al. (2013). Figure 11 illustrates the impact of $B$ and $g$ variations on the retrieval of LAP concentrations. The numerical analysis shows that the relative impact of shape parameter variations on the estimation is independent of the SSA and LAP concentration values. Overall, $B$ variations lead to $-10 \%$, $+25 \%$ uncertainty on impurity estimation. The variations of $g$ do not impact LAP retrievals since SSA is left as a free parameter in our method and can counterbalance any variation of $g$ (see Eq. 12).

Uncertainties on the imaginary part of the refractive index of ice may also slightly impact our results. The values proposed by Warren et al. (2006), being lower than the one of Picard et al. (2016) used in this study, would lead to less absorbing ice in the spectral range 400-600 nm, implying higher estimates of LAP concentrations. This would increase the bias observed in Fig. 8 of around $1 \mathrm{ng} \mathrm{g}^{-1}$ eqBC (estimate not shown). The impact is low regarding other sources of uncertainties and is not further explored.

\subsection{SIP spectral information}

Figure 12 illustrates the impact of considering only one type of LAP (BC here) instead of two in our retrieval algorithm. In a first example of ZOI (Fig. 12a), the absorption is dominated by $\mathrm{BC}$, and both retrievals have similar performances considering dust or not. In a second ZOI (Fig. 12b), dust is clearly 

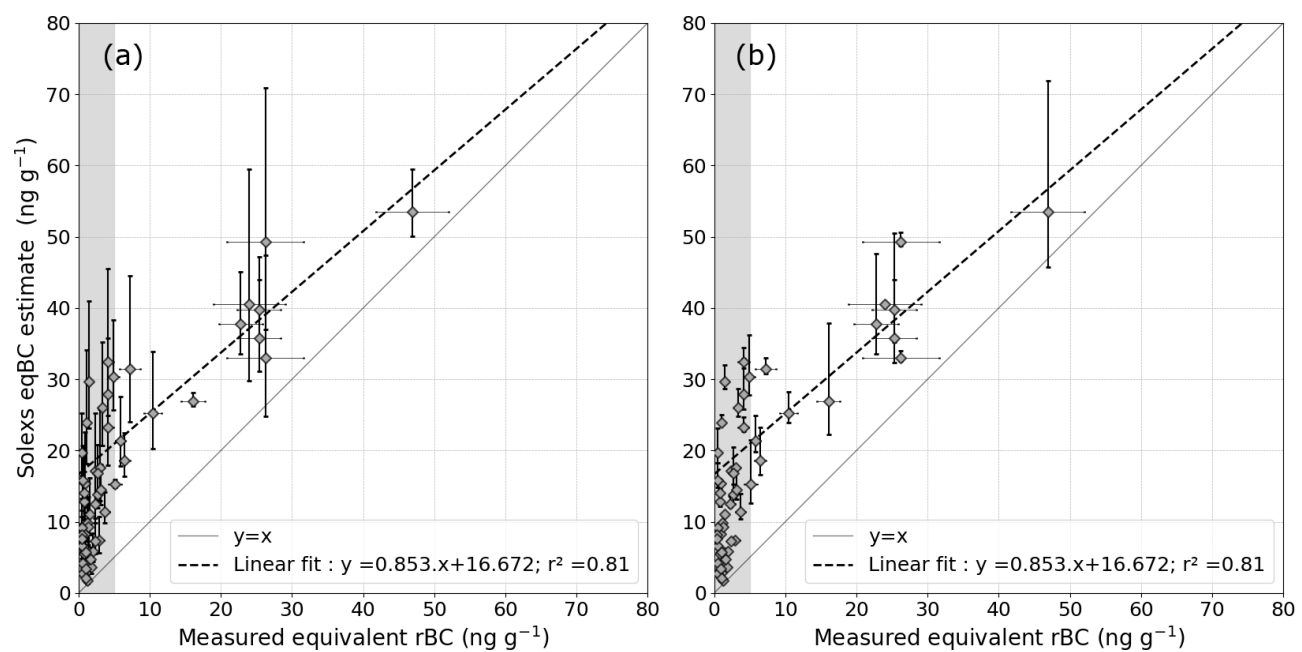

Figure 9. Comparison between measured and estimated eqBC concentrations for all the ZOIs with concomitant LAP measurements. The grey shading corresponds to the zone below the sensitivity limit of our method (i.e. $5 \mathrm{ng} \mathrm{g}^{-1}$ ). (a) Error bars show how uncertainties on BC MAE affect LAP estimates. (b) Error bars show how uncertainties on dust MAE affect LAP estimates.

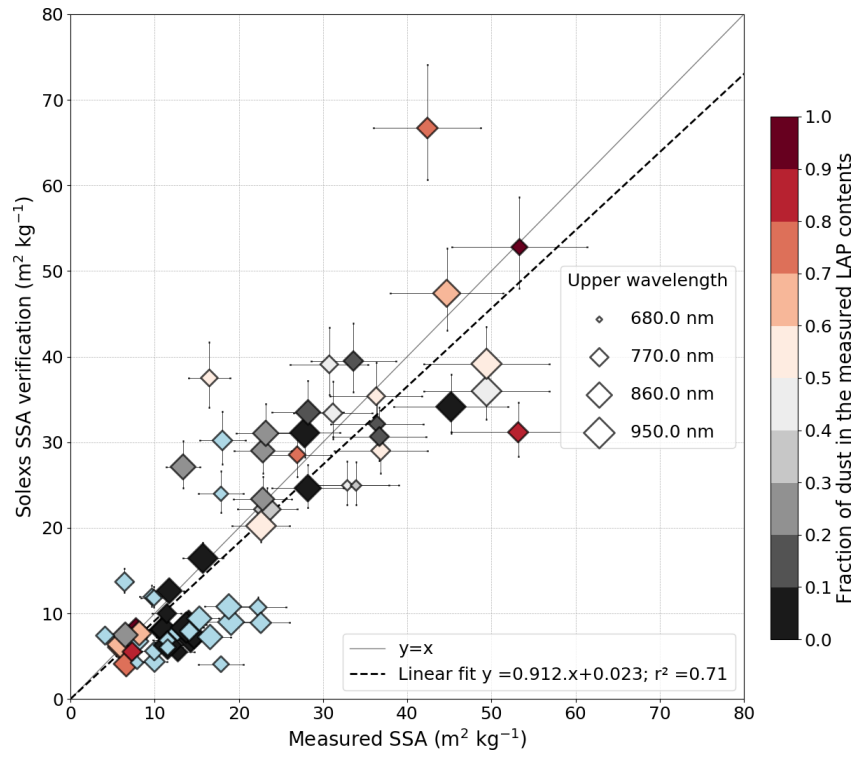

Figure 10. Comparison between measured and estimated SSA for all the ZOIs with concomitant SSA measurement. The colour of the symbols corresponds to the proportion of LAP absorption coming from dust, and sizes are related to the upper wavelength of the AFEC estimation. Symbols are blue when chemical measurements are not available.

the dominant absorber and has been measured with a concentration of about $13 \mu \mathrm{gg}^{-1}$. In this case the estimated AFEC from the retrieval algorithm does not reproduce the measured one by accounting only for $\mathrm{BC}$. The presence of a different LAP type with a higher Ångström exponent, dust here, is necessary to explain the spectral signature of the AFEC in the visible.

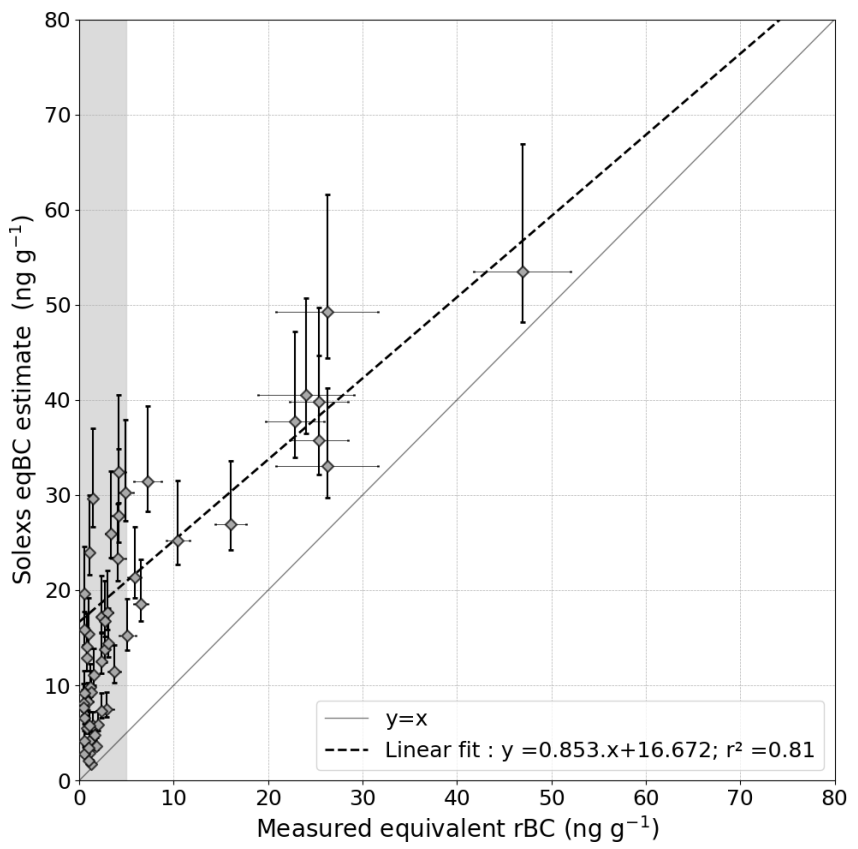

Figure 11. Comparison between measured and estimated eqBC concentrations for all the ZOIs with concomitant LAP measurement. The grey shading corresponds to the zone below the sensitivity limit of our method (i.e. $5 \mathrm{ng} \mathrm{g}_{-1}$ ). Error bars show how uncertainties on the enhancement parameter of ice B affect the LAP retrieval algorithm.

In order to investigate if finer information on the LAP prevailing type can be retrieved, the estimated contribution of dust to the total LAP impact ( $\eta_{\text {est }}$ from Eq. 2 ) is shown in Fig. 13 and compared to the measured dust proportion over the $14 \mathrm{ZOIs}$ with a measured eqrBC concentration higher 

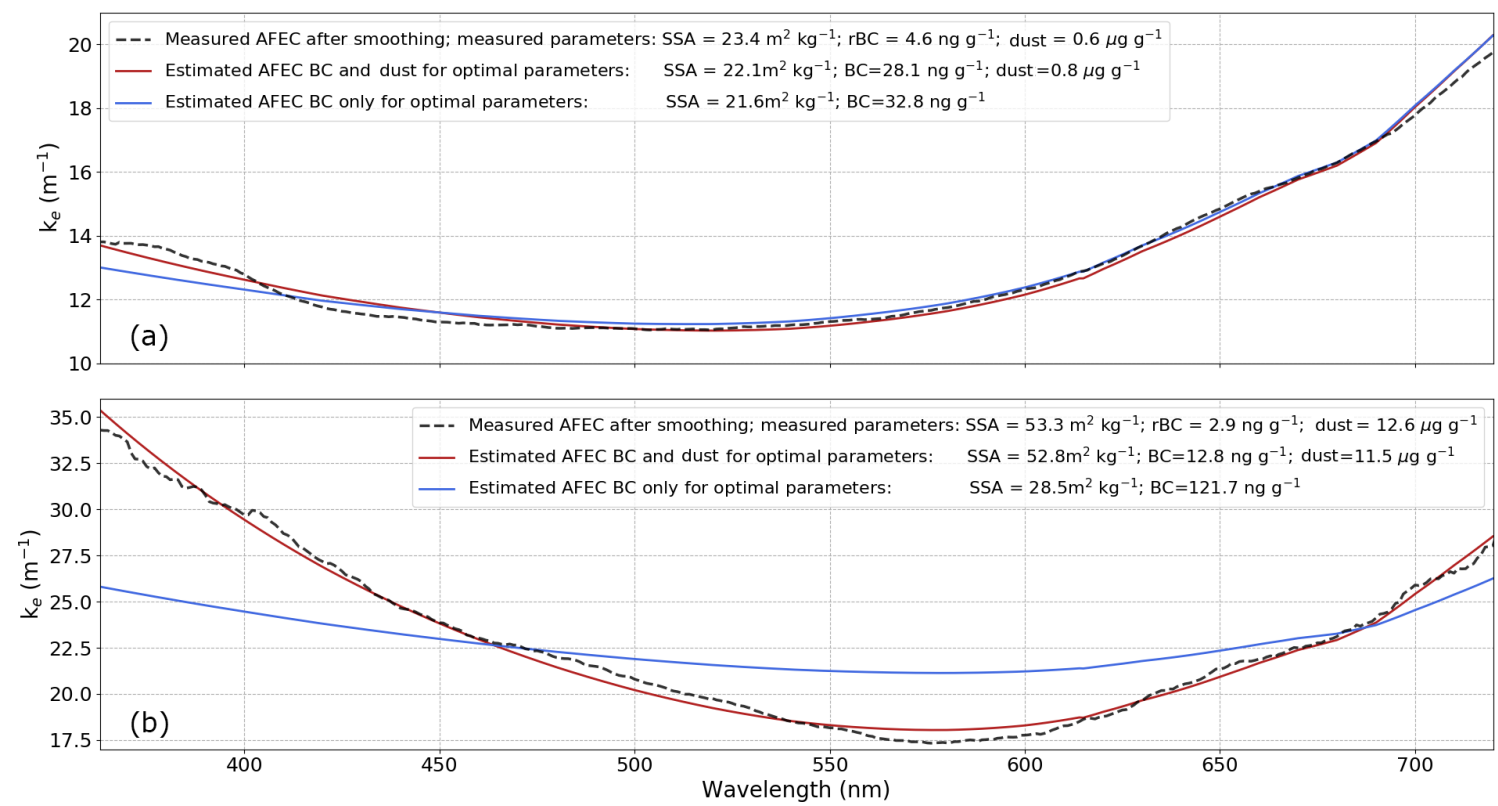

Figure 12. AFEC measured (black dotted line) and estimated considering both dust and BC (red curves) or considering only BC (blue curves) in the retrieval algorithm. (a) On a ZOI located between 11 and $14 \mathrm{~cm}$ on the SOLEXS profile 002 measured on 23 February 2018 , where LAP absorption is dominated by BC. (b) On a ZOI located between 33 and $36 \mathrm{~cm}$ on the SOLEXS profile 004 measured on 1 October 2018 , where LAP absorption is dominated by dust (around $10 \mu \mathrm{gg}^{-1}$ of dust measured).

than $5 \mathrm{ng} \mathrm{g}^{-1}$. The retrieval method is sensitive to the type of LAP present in the snowpack with a low $\eta_{\text {est }}$ when BC dominates (median value of 0.1 ) and higher values of $\eta_{\text {est }}$ when dust dominates (median value of 0.6). At this stage of development, only these cases can be distinguished but not quantitative measure of the relative contribution. The estimated dust fraction is almost systematically lower than the measured dust fraction (12/14 points). This may either indicate that the relative absorption of dust versus BC used in this study could be improved or that there are systematic biases in dust or $\mathrm{rBC}$ measurements. However, the small number of validation points and the presence of dust in most of the ZOIs where measured eqrBC concentrations are higher than $5 \mathrm{ng} \mathrm{g}^{-1}$ make it difficult to draw a reliable conclusion, and this result has to be taken with care.

\subsection{Impact of liquid water}

Figure 14 shows an example of application of our method to a ZOI containing liquid water. The estimated LAP concentration is 1 order of magnitude higher than the measured one. A similar phenomenon has been systematically observed in the $16 \mathrm{ZOIs}$ in which liquid water is present, which is why they were discarded from Fig. 8. The measured AFEC is abnormally high between 350 and $700 \mathrm{~nm}$ in regard to the measured LAP concentration, causing a strong overestimation of LAP concentrations. Further investigation is needed to understand the cause, but the consequence is that information

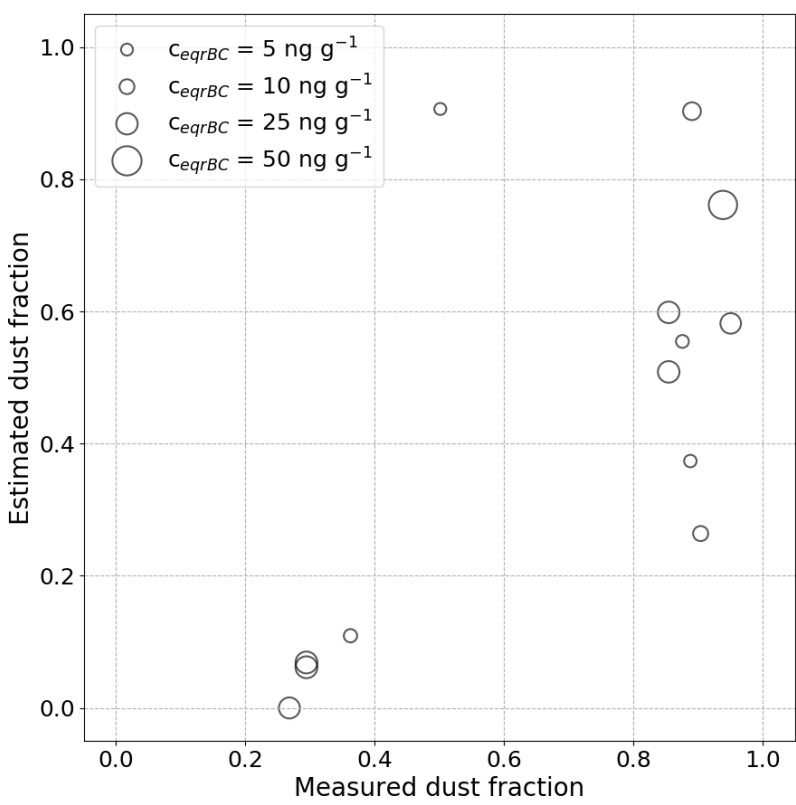

Figure 13. Comparison between measured and estimated proportion of LAP absorption coming from dust for all the ZOIs with concomitant LAP measurements. The size of symbols corresponds to the measured eqBC concentration of the associated ZOI.

about LAPs cannot be retrieved in the presence of liquid water with our methodology. 


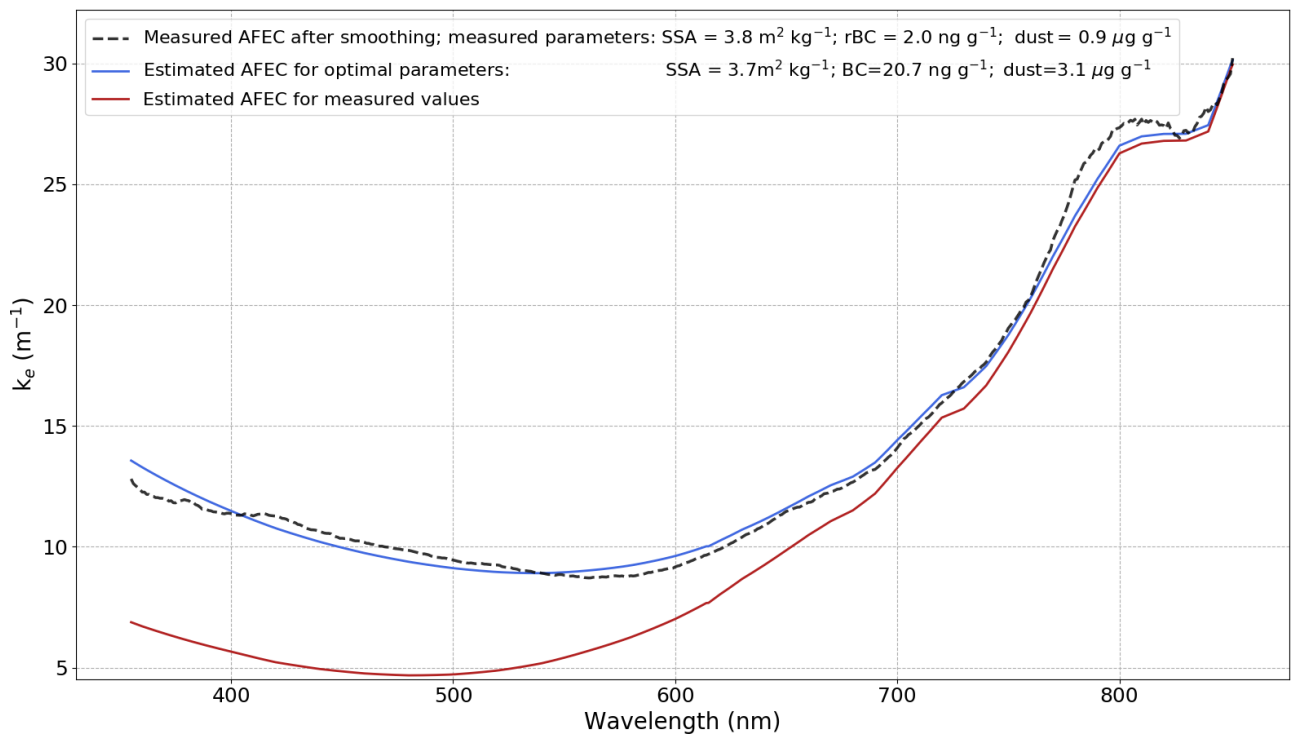

Figure 14. AFEC computation on a ZOI containing liquid water (between 15 and $18 \mathrm{~cm}$ on the SOLEXS profile 002 measured on 28 March 2017). The measured AFEC after filtering (black dotted line) is compared to the AFEC modelled using optimal parameters (blue curve) and to the AFEC modelled with measured values (red curves).

\section{Discussion}

\subsection{Discrepancy between measured LAP concentrations and induced absorption}

Figure 8 shows a correlation between LAP concentrations estimated from SIP and chemically measured ones, which suggests that easy measurements of the optical impact of LAPs may be possible in the future. However, there is still a strong uncertainty and clear positive bias between impurity contents estimated from the measured AFEC and the measured ones. Most of the uncertainties may be due to uncaught variations of LAP optical properties (Fig. 9) and snow physical parameters (Fig. 11), which is illustrated by the fact that, when subtracting the $15.7 \mathrm{ng} \mathrm{g}^{-1}$ eqBC positive bias, all measured LAP concentrations higher than $5 \mathrm{ng} \mathrm{g}^{-1}$ are within the range of uncertainty of the retrieval.

Even with the aforementioned uncertainties, the eqBC concentration retrieved in some ZOIs does not match the measurements. This suggests that for a given measured concentration of LAPs, the radiative impact induced on snow absorption is too low. We see three potential explanations for this.

- A problem in our SIP measurements cannot be excluded: the disturbance caused by the fibre rod is discussed in Sect. 5.3. However, France et al. (2012) also noticed that $\mathrm{BC}$ and humic-like substances estimated from SIP measurements were abnormally higher than the one measured at the same location during the OASIS campaign (Voisin et al., 2012). As they used a dif- ferent measurement technique, the bias is probably not due to the measurement technique.

- The problem may come from chemical measurements of LAPs in snow. The bias observed here could be explained by a systematic underestimation of chemically measured LAP concentrations in snow as suggested in Schwarz et al. (2012) for BC. The particle size of BC was found to be larger in snow than in the atmosphere (Schwarz et al., 2013), which may lead to the underestimation of measured $\mathrm{rBC}$ concentrations because the larger sizes are not detected by the $\mathrm{SP}^{2}$. This is partly accounted for in the chemical data processing but implicitly depends on having an external calibrant with a size distribution close enough to that of the actual BC in snow. The calibrant chosen here (Wendl et al., 2014) reduces the underestimation to a minimum, without excluding it totally. As for dust, our measurements present potential biases in both directions: some sedimentation during the handling of the sample is always possible, although our protocol was designed to minimise the risk (the samples are gently shaken while waiting for analysis). In contrast, we assume that all the measured insoluble particles above $0.6 \mu \mathrm{m}$ are light-absorbing dust, which may lead to overestimating the dust concentrations: some of the higher size particles might be nonlight-absorbing dust (such as quartz or calcite). It is thus unlikely that the whole bias can be explained with this sole hypothesis.

- This suggests a third hypothesis: our LAP MAE uncertainty estimation does not span across a wide-enough 
range. LAP enhancement absorption when deposited in snow may be underestimated due to LAP-snow physico-chemical interactions. The absorption enhancement of LAPs is often attributed to internal mixing of LAPs in snow (e.g. Flanner et al., 2012) but might be partly due to other physical processes such as coating of LAPs in snow. This process remains poorly investigated in snow (e.g. He et al., 2014; Dong et al., 2018) despite its strong impact on LAP absorption in the atmosphere (Moffet and Prather, 2009).

\subsection{Impact of water}

Figure 14 reveals a strong unexplained extinction enhancement in the visible if liquid water is present. This phenomenon has been observed in all ZOIs containing liquid water. In some cases, an abnormally high extinction is also observed in the NIR part of the spectra. We propose two possible explanations. First, liquid water may enhance LAP absorption due to chemical or optical interactions, having a consequent impact on light extinction. For instance, the inclusion of externally mixed LAPs in liquid water might cause a lensing effect, increasing consequently the MAE of the present LAPs. Mikhailov et al. (2006) suggest that soot-water drop aggregates can enhance absorption of the soot particle by a factor up to 3 compared to the sole particle. This could explain the extinction enhancement observed on the AFEC of layers containing liquid water observed in Sect. 4.5. Second, it might be due to an experimental problem as the hole in which the fibre is inserted is made of air. In the case of a very wet snowpack, inserting the metal rod into the snowpack may create a water lens around the rod, creating an additional air-water interface around the optic fibre. This might perturb the SIP measurement and in turn the AFEC.

Libois et al. (2013) tried to determine the value of the shape parameter $B$ from data in the literature based on AFEC estimations with concomitant reflectance measurements. The two values of $B$ retrieved for snowpacks containing liquid water are questionable, which may originate from the same issue observed in our study.

\subsection{Additional sources of error in the measurements}

\subsubsection{Impact of the rod}

The uncertainties affecting SIP measurements with the technique used in this study have been assessed in Picard et al. (2016) for pristine snow. As the measurement protocol advised by their study has been strictly followed in our SIP measurements, they suggest that uncertainties are expected to be less than $1 \mathrm{ng} \mathrm{g}^{-1}$ eqBC. In the study of Picard et al. (2016) the impact of the rod is significant below 500 nanometres for extremely small amounts of LAPs (about $1 \mathrm{ng} \mathrm{g}^{-1}$ ), i.e. AFEC around $5 \mathrm{~m}^{-1}$. Despite the higher level of LAPs in Alpine than Antarctic snow, we also observe on our SIP mea- surements some non-physical behaviour at the transitions between the homogeneous layers that Picard et al. (2016) estimated to be only possible for pristine snow. This includes for instance short zones in the profiles with increasing radiance with depth (e.g. in Fig. 3a around $32 \mathrm{~cm}$ depth). This clearly violates the radiative transfer theory for 1-D plane parallel media and might explain a part of the uncertainties of the present method, especially for low impurity contents. Figure 8 clearly shows that retrieval under $5 \mathrm{ng} \mathrm{g}^{-1}$ is not possible, spotlighting a strong dispersion of the LAP estimation which might be partly explained by the impact of the rod.

\subsubsection{Presence of other LAPs}

Here, we consider $\mathrm{BC}$ and dust to be the only absorbers present in the snowpack. The presence of other LAP types in the snowpack uncaptured by our chemical measurements might explain a part of the bias between optically retrieved and chemically measured LAP concentrations observed in this study. For instance, organic carbon (OC) may play an important role in snowpack absorption (Lin et al., 2014; Wang et al., 2019). However, the peak absorption of OC is located between 350 and $400 \mathrm{~nm}$, and the impact at wavelengths higher than $400 \mathrm{~nm}$ is expected to be limited (Chen and Baker, 2010). It is hence expected to have a low impact on this work though more impact for photochemistry in the UV.

\subsubsection{Spectral signature of LAPs}

In addition to the uncertainty on absorption efficiency of LAPs discussed in Sect. 4.2, the spectral signature of LAP absorption can also vary. For BC, the absorption Ångström exponent is around 1 and is not expected to vary significantly (Bond and Bergstrom, 2006). On the contrary, the dust Ångström exponent can vary from 2 to 5 depending on the source and size distribution of dust (e.g. Caponi et al., 2017) and is assumed to be to 4.1 in the present study (Libyan dust). Considering a different Ångström exponent for dust would not impact significantly the eqBC retrieval but would modify the partition of LAP impact between dust and BC.

\section{Conclusion}

This paper presents a unique dataset including two seasons of near-weekly surveys of snow physical properties (SSA, density) associated with measurements of spectral irradiance profiles (SIPs). The asymptotic flux extinction coefficient (AFEC) is estimated from SIP measurement in homogeneous layers of the snowpack in the visible and NIR. In each layer, we determine the optimal LAP concentration explaining the measured spectral AFEC using the asymptotic approximation of the radiative transfer theory (AART; Kokhanovsky and Zege, 2004). Through a comparison of these optimal LAP concentrations with chemical LAP measurements, we 
demonstrate that valuable information on properties of LAPs in snow can be estimated from SIP measurements.

For the first time, we compare the spectral signal of LAPs with snow extinction and chemical analyses of LAP concentrations. For now, the limit of sensitivity of our method is around $5 \mathrm{ng} \mathrm{g}^{-1}$, and smaller concentrations cannot be detected. For higher concentrations, we highlight a correlation between estimated eqBC concentrations and measured ones $\left(r^{2}=0.81\right)$. We also demonstrate that the spectral information of LAPs can be retrieved from SIP measurements. It is possible to determine the prevailing type of LAPs present in a layer based on its spectral signature. However, the reliability of this method is relatively poor for now. Our results suggest that LAP absorption is enhanced in layers containing liquid water, where our method does not apply. This might come from the formation of LAP-water aggregates as described in Mikhailov et al. (2006) or from a measurement artefact. The method proposed also gives valuable information on snow physical properties which are left as a free parameter. We verify that the estimated snow properties are consistent with measurements, demonstrating a good correlation between estimated SSA and in situ SSA measured by NIR reflectometry $\left(R^{2}=0.71\right)$.

This study is a promising first step to easily determine vertical profiles of LAP concentrations within the snowpack. However, the accuracy of our retrieval method is low and a marked positive bias of around $16 \mathrm{ng} \mathrm{g}^{-1}$ eqBC is observed. The low accuracy is not surprising given the strong uncertainties of LAP absorption efficiency and of snow physical parameters in the modelling. Nevertheless, the cause of the bias cannot be explained assuming reasonable uncertainties in the modelling parameters. The potential causes of the bias discussed raise different issues: SIP measurement uncertainties, chemical measurement uncertainties, or underestimation of LAPs in snow absorption enhancement due to interactions between LAPs and snow. The bias between LAP radiative impact and chemical measurements is challenging to address owing to several reasons. Firstly, chemical measurements in snow are time consuming and are affected by many uncertainties such as the dependence on the size distribution of the particles or the nebulisation biases. Secondly, LAP optical properties in snow are highly variable and their evolution is poorly understood. The mixing state, the coating or the presence of liquid water affect the absorption efficiency of LAPs and need to be further investigated. Thirdly, uncertainties on snow microstructure introduce high uncertainties in the retrieval method. Using Monte Carlo ray tracing on real micro-tomography snow samples might be a way to better understand these parameters along with snow metamorphism (Kaempfer et al., 2007). Any advances on one of these points are expected to lower the uncertainties affecting LAP absorption efficiency in snow and in turn the method presented here. As SIP measurements are much faster than manually collecting profiles of chemical measurements, our method could be attractive as an alternative to extract vertically resolved information on LAP concentrations in snow.

Code and data availability. The datasets analysed during this study and the code used to produce the figures are available from the corresponding author on request. 
Appendix A: Summary of the acronyms used in the present study

$\begin{array}{ll}\text { Acronym } & \text { Full name } \\ \text { SIP } & \text { Spectral irradiance profile } \\ \text { LAP } & \text { Light-absorbing particle } \\ \text { AFEC } & \text { Asymptotic flux extinction coefficient } \\ \text { SSA } & \text { Specific surface area } \\ \text { MAE } & \text { Mass absorption efficiency } \\ \text { ZOI } & \text { Zone of interest } \\ \text { BC } & \text { Black carbon } \\ \text { rBC } & \text { Refractory black carbon } \\ \text { eqBC } & \text { Equivalent black carbon } \\ \text { eqrBC } & \text { Equivalent refractory black carbon } \\ \text { NIR } & \text { Near infrared }\end{array}$


Author contributions. FT led the study and was in charge of the field measurement campaign over the two seasons. FT along with MD and GP performed the major part of the data analysis. LA and GP developed the SOLEXS instrument and the code library to process the measured spectral irradiance profile data. DV supervised the chemical measurement analysis. ML, FL and JR contributed significantly to the field data acquisition. All authors contributed to the manuscript.

Competing interests. The authors declare that they have no conflict of interest.

Acknowledgements. CNRM/CEN and IGE are part of Labex OSUG@2020 (investissement d'avenir - ANR10 LABX56). This study was supported by the ANR programs 1-JS56-005-01 MONISNOW and ANR-16-CE01-0006 EBONI; the INSR/LEFE projects BON and ASSURANCE; and the Ecole Doctorale SDU2E of Toulouse. This research was at least partially supported by Lautaret Garden - UMS 3370 (Univ. Grenoble Alpes, CNRS, SAJF, 38000 Grenoble, France), member of AnaEE France (ANR-11-INBS0001AnaEE-Services, Investissements d'Avenir frame) and of the eLTER European network (Univ. Grenoble Alpes, CNRS, LTSER Zone Atelier Alpes, 38000 Grenoble, France). The authors are grateful to LISA and PSI for chemical analysis of snow samples presented in this study. Jesus Revuelto is supported by a Post-doctoral Fellowship of the AXA research fund (ref. CNRM 3.2.01/17). The authors would like to thank the editor, the reviewers and the typesetter for their precious help in improving our manuscript. The authors are also very grateful to all the people that helped perform the field measurements and chemical analyses: Bertrand Cluzet, Ines Ollivier, Clement Delcourt, Paul Billecocq, Natasha Bradford, Anthony Vella, Vincent Lucaire, François Besson, Matthieu Vernay, Frederic Flin, Céline Vargel and Mark Flanner. Finally, special thanks to Jacques Roulle for his commitment to fixing the field instruments, his help in the field, and his precious insight.

Financial support. This research has been supported by the ANR (grant nos. ANR-16-CE01-0006 EBONI and 1-JS56-005-01 MONISNOW).

Review statement. This paper was edited by Mark Flanner and reviewed by two anonymous referees.

\section{References}

Adolph, A. C., Albert, M. R., Lazarcik, J., Dibb, J. E., Amante, J. M., and Price, A.: Dominance of grain size impacts on seasonal snow albedo at open sites in New Hampshire, J. Geophys. Res.Atmos., 122, 121-139, 2017.

Aoki, T., Motoyoshi, H., Kodama, Y., Yasunari, T. J., Sugiura, K., and Kobayashi, H.: Atmospheric aerosol deposition on snow surfaces and its effect on albedo, SOLA, 2, 13-16, 2006.
Aoki, T., Kuchiki, K., Niwano, M., Kodama, Y., Hosaka, M., and Tanaka, T.: Physically based snow albedo model for calculating broadband albedos and the solar heating profile in snowpack for general circulation models, J. Geophys. Res., 116, D11114, https://doi.org/10.1029/2010JD015507, 2011.

Armstrong, R. and Brun, E.: Snow and climate: physical processes, surface energy exchange and modeling, Cambridge University Press, UK, 2008.

Arnaud, L., Picard, G., Champollion, N., Domine, F., Gallet, J.-C., Lefebvre, E., Fily, M., and Barnola, J.-M.: Measurement of vertical profiles of snow specific surface area with a $1 \mathrm{~cm}$ resolution using infrared reflectance: instrument description and validation, J. Glaciol., 57, 17-29, https://doi.org/10.3189/002214311795306664, 2011.

Bond, T. C. and Bergstrom, R. W.: Light absorption by carbonaceous particles: An investigative review, Aerosol Sci. Tech., 40, 27-67, 2006.

Box, J. E., Fettweis, X., Stroeve, J. C., Tedesco, M., Hall, D. K., and Steffen, K.: Greenland ice sheet albedo feedback: thermodynamics and atmospheric drivers, The Cryosphere, 6, 821-839, https://doi.org/10.5194/tc-6-821-2012, 2012.

Brandt, R. E. and Warren, S. G.: Solar-heating rates and temperature profiles in Antarctic snow and ice, J. Glaciol., 39, 99-110, 1993.

Caponi, L., Formenti, P., Massabó, D., Di Biagio, C., Cazaunau, M., Pangui, E., Chevaillier, S., Landrot, G., Andreae, M. O., Kandler, K., Piketh, S., Saeed, T., Seibert, D., Williams, E., Balkanski, Y., Prati, P., and Doussin, J.-F.: Spectral- and size-resolved mass absorption efficiency of mineral dust aerosols in the shortwave spectrum: a simulation chamber study, Atmos. Chem. Phys., 17, 7175-7191, https://doi.org/10.5194/acp-17-7175-2017, 2017.

Chen, S. and Baker, I.: Evolution of individual snowflakes during metamorphism, J. Geophys. Res., 115, D21114, https://doi.org/10.1029/2010JD014132, 2010.

Colbeck, S. C.: An overview of seasonal snow metamorphism, Rev. Geophys., 20, 45-61, https://doi.org/10.1029/RG020i001p00045, 1982.

Cook, J., Hodson, A., Taggart, A., Mernild, S., and Tranter, M.: A predictive model for the spectral "bioalbedo" of snow, J. Geophys. Res.-Earth, 122, 434-454, 2017.

Dal Farra, A., Kaspari, S., Beach, J., Bucheli, T. D., Schaepman, M., and Schwikowski, M.: Spectral signatures of submicron scale light-absorbing impurities in snow and ice using hyperspectral microscopy, J. Glaciol., 64, 377-386, 2018.

Delmonte, B., Petit, J., Andersen, K. K., Basile-Doelsch, I., Maggi, V., and Lipenkov, V. Y.: Dust size evidence for opposite regional atmospheric circulation changes over east Antarctica during the last climatic transition, Clim. Dynam., 23, 427-438, 2004.

Di Mauro, B., Fava, F., Ferrero, L., Garzonio, R., Baccolo, G., Delmonte, B., and Colombo, R.: Mineral dust impact on snow radiative properties in the European Alps combining ground, UAV, and satellite observations, J. Geophys. Res.-Atmos., 120, 6080 6097, 2015.

Di Mauro, B., Garzonio, R., Rossini, M., Filippa, G., Pogliotti, P., Galvagno, M., Morra di Cella, U., Migliavacca, M., Baccolo, G., Clemenza, M., Delmonte, B., Maggi, V., Dumont, M., Tuzet, F., Lafaysse, M., Morin, S., Cremonese, E., and Colombo, R.: Saharan dust events in the European Alps: role in snowmelt and geochemical characterization, The Cryosphere, 13, 1147-1165, https://doi.org/10.5194/tc-13-1147-2019, 2019. 
Doherty, S. J., Warren, S. G., Grenfell, T. C., Clarke, A. D., and Brandt, R. E.: Light-absorbing impurities in Arctic snow, Atmos. Chem. Phys., 10, 11647-11680, https://doi.org/10.5194/acp-1011647-2010, 2010.

Domine, F., Albert, M., Huthwelker, T., Jacobi, H.-W., Kokhanovsky, A. A., Lehning, M., Picard, G., and Simpson, W. R.: Snow physics as relevant to snow photochemistry, Atmos. Chem. Phys., 8, 171-208, https://doi.org/10.5194/acp-8171-2008, 2008.

Dong, Z., Kang, S., Qin, D., Shao, Y., Ulbrich, S., and Qin, $\mathrm{X}$.: Variability in individual particle structure and mixing states between the glacier-snowpack and atmosphere in the northeastern Tibetan Plateau, The Cryosphere, 12, 3877-3890, https://doi.org/10.5194/tc-12-3877-2018, 2018.

Dumont, M., Arnaud, L., Picard, G., Libois, Q., Lejeune, Y., Nabat, P., Voisin, D., and Morin, S.: In situ continuous visible and nearinfrared spectroscopy of an alpine snowpack, The Cryosphere, 11, 1091-1110, https://doi.org/10.5194/tc-11-1091-2017, 2017.

Fierz, C., Armstrong, R. L., Durand, Y., Etchevers, P., Greene, E., McClung, D. M., Nishimura, K., Satyawali, P. K., and Sokratov, S. A.: The international classification for seasonal snow on the ground, UNESCO, Paris, IHP-VII Technical Documents in Hydrology no. 83, IACS Contribution no. 1, available at: http: //unesdoc.unesco.org/images/0018/001864/186462e.pdf (last access: 6 August 2019), 2009.

Flanner, M. G., Liu, X., Zhou, C., Penner, J. E., and Jiao, C.: Enhanced solar energy absorption by internally-mixed black carbon in snow grains, Atmos. Chem. Phys., 12, 4699-4721, https://doi.org/10.5194/acp-12-4699-2012, 2012.

Flanner, M. G. and Zender, C. S.: Snowpack radiative heating: Influence on Tibetan Plateau climate, Geophys. Res. Lett., 32, L06501, https://doi.org/10.1029/2004GL022076, 2005.

Flanner, M. G. and Zender, C. S.: Linking snowpack microphysics and albedo evolution, J. Geophys. Res., 111, D12208, https://doi.org/10.1029/2005JD006834, 2006.

France, J. L., Reay, H. J., King, M. D., Voisin, D., Jacobi, H., Beine, H. J., Anastasio, C., MacArthur, A., and Lee-Taylor, J.: Hydroxyl radical and $\mathrm{NO}_{x}$ production rates, black carbon concentrations and light-absorbing impurities in snow from field measurements of light penetration and nadir reflectivity of on-shore and offshore coastal Alaskan snow, J. Geophys. Res., 117, D00R12, https://doi.org/10.1029/2011JD016639, 2012.

Gallet, J.-C., Domine, F., Zender, C. S., and Picard, G.: Measurement of the specific surface area of snow using infrared reflectance in an integrating sphere at 1310 and $1550 \mathrm{~nm}$, The Cryosphere, 3, 167-182, https://doi.org/10.5194/tc-3-167-2009, 2009.

Grannas, A. M., Jones, A. E., Dibb, J., Ammann, M., Anastasio, C., Beine, H. J., Bergin, M., Bottenheim, J., Boxe, C. S., Carver, G., Chen, G., Crawford, J. H., Dominé, F., Frey, M. M., Guzmán, M. I., Heard, D. E., Helmig, D., Hoffmann, M. R., Honrath, R. E., Huey, L. G., Hutterli, M., Jacobi, H. W., Klán, P., Lefer, B., McConnell, J., Plane, J., Sander, R., Savarino, J., Shepson, P. B., Simpson, W. R., Sodeau, J. R., von Glasow, R., Weller, R., Wolff, E. W., and Zhu, T.: An overview of snow photochemistry: evidence, mechanisms and impacts, Atmos. Chem. Phys., 7, 43294373, https://doi.org/10.5194/acp-7-4329-2007, 2007.

Hadley, O. L. and Kirchstetter, T. W.: Black-carbon reduction of snow albedo, Nat. Clim. Change, 2, 437-440, 2012.
Hall, A.: The role of surface albedo feedback in climate, J. Climate, 17, 1550-1568, 2004.

He, C., Li, Q., Liou, K.-N., Takano, Y., Gu, Y., Qi, L., Mao, Y., and Leung, L. R.: Black carbon radiative forcing over the Tibetan Plateau, Geophys. Res. Lett., 41, 7806-7813, 2014.

He, C., Takano, Y., Liou, K.-N., Yang, P., Li, Q., and Chen, F.: Impact of Snow Grain Shape and Black Carbon-Snow Internal Mixing on Snow Optical Properties: Parameterizations for Climate Models, J. Climate, 30, 10019-10036, 2017.

Joseph, J. H., Wiscombe, W., and Weinman, J.: The delta-Eddington approximation for radiative flux transfer, J. Atmos. Sci., 33, 2452-2459, 1976.

Kaempfer, T. U., Hopkins, M., and Perovich, D.: A threedimensional microstructure-based photon-tracking model of radiative transfer in snow, J. Geophys. Res., 112, D24113, https://doi.org/10.1029/2006JD008239, 2007.

King, J., Connolley, W., and Derbyshire, S.: Sensitivity of modelled Antarctic climate to surface and boundary-layer flux parametrizations, Q. J. Roy. Meteor. Soc., 127, 779-794, 2001.

Kokhanovsky, A. and Zege, E.: Scattering optics of snow, Appl. Optics, 43, 1589-1602, https://doi.org/10.1364/AO.43.0001589, 2004.

Kokhanovsky, A. A.: Light scattering media optics, Springer Science \& Business Media, Germany, 2004.

Legagneux, L., Cabanes, A., and Domine, F.: Measurement of the specific surface area of 176 snow samples using methane adsorption at $77 \mathrm{~K}$, J. Geophys Res., 107, 4335, https://doi.org/10.1029/2001JD001016, 2002.

Libois, Q.: Evolution des propriétés physiques de neige de surface sur le plateau Antarctique. Observations et modélisation du transfert radiatif et du métamorphisme, $\mathrm{PhD}$ thesis, Grenoble, France, 2014.

Libois, Q., Picard, G., France, J. L., Arnaud, L., Dumont, M., Carmagnola, C. M., and King, M. D.: Influence of grain shape on light penetration in snow, The Cryosphere, 7, 1803-1818, https://doi.org/10.5194/tc-7-1803-2013, 2013.

Libois, Q., Picard, G., Dumont, M., Arnaud, L., Sergent, C., Pougatch, E., Sudul, M., and Vial, D.: Experimental determination of the absorption enhancement parameter of snow, J. Glaciol., 60, 714-724, 2014.

Liljequist, G. H.: Energy exchange of an antarctic snow-field: A, Short-wave radiation; B. Long-wave radiation and radiation balance. Norweigian-British-Swedish Antarctic Expedition 19491952, Scientific Results, 2, 1-184, 1956.

Lim, S., Faïn, X., Zanatta, M., Cozic, J., Jaffrezo, J.-L., Ginot, P., and Laj, P.: Refractory black carbon mass concentrations in snow and ice: method evaluation and inter-comparison with elemental carbon measurement, Atmos. Meas. Tech., 7, 3307-3324, https://doi.org/10.5194/amt-7-3307-2014, 2014.

Lin, G., Penner, J. E., Flanner, M. G., Sillman, S., Xu, L., and Zhou, C.: Radiative forcing of organic aerosol in the atmosphere and on snow: Effects of SOA and brown carbon, J. Geophys. Res.Atmos., 119, 7453-7476, 2014.

Mikhailov, E., Vlasenko, S., Podgorny, I., Ramanathan, V., and Corrigan, C.: Optical properties of soot-water drop agglomerates: An experimental study, J. Geophys. Res., 111, D07209, https://doi.org/10.1029/2005JD006389, 2006. 
Moffet, R. C. and Prather, K. A.: In-situ measurements of the mixing state and optical properties of soot with implications for radiative forcing estimates, P. Natl. Acad. Sci. USA, 106, 1187211877, 2009.

Painter, T. H., Flanner, M. G., Kaser, G., Marzeion, B., VanCuren, R. A., and Abdalati, W.: End of the Little Ice Age in the Alps forced by industrial black carbon, P. Natl. Acad. Sci. USA, 110, 15216-15221, 2013.

Picard, G., Domine, F., Krinner, G., Arnaud, L., and Lefebvre, E.: Inhibition of the positive snow-albedo feedback by precipitation in interior Antarctica, Nat. Clim. Change, 2, 795, https://doi.org/10.1038/nclimate1590, 2012.

Picard, G., Libois, Q., and Arnaud, L.: Refinement of the ice absorption spectrum in the visible using radiance profile measurements in Antarctic snow, The Cryosphere, 10, 2655-2672, https://doi.org/10.5194/tc-10-2655-2016, 2016.

Proksch, M., Rutter, N., Fierz, C., and Schneebeli, M.: Intercomparison of snow density measurements: bias, precision, and vertical resolution, The Cryosphere, 10, 371-384, https://doi.org/10.5194/tc-10-371-2016, 2016.

Reay, H., France, J., and King, M.: Decreased albedo, e-folding depth and photolytic $\mathrm{OH}$ radical and $\mathrm{NO}_{2}$ production with increasing black carbon content in Arctic snow, J. Geophys. Res., 117, D00R20, https://doi.org/10.1029/2011JD016630, 2012.

Ricchiazzi, P., Yang, S., Gautier, C., and Sowle, D.: SBDART: A research and teaching software tool for plane-parallel radiative transfer in the earth's atmosphere, B. Am. Meteorol. Soc., 79, 2101-2114, 1998.

Richardson, S. G. and Salisbury, F. B.: Plant Responese to the Light Penetrating Snow, Ecology, 58, 1152-1158, 1977.

Schnaiter, M., Linke, C., Möhler, O., Naumann, K.-H., Saathoff, H., Wagner, R., Schurath, U., and Wehner, B.: Absorption amplification of black carbon internally mixed with secondary organic aerosol, J. Geophys. Res., 110, D19204, https://doi.org/10.1029/2005JD006046, 2005.

Schwarz, J., Gao, R., Perring, A., Spackman, J., and Fahey, D.: Black carbon aerosol size in snow, Scientific reports, 3, 1356, https://doi.org/10.1038/srep01356, 2013.

Schwarz, J. P., Doherty, S. J., Li, F., Ruggiero, S. T., Tanner, C. E., Perring, A. E., Gao, R. S., and Fahey, D. W.: Assessing Single Particle Soot Photometer and Integrating Sphere/Integrating Sandwich Spectrophotometer measurement techniques for quantifying black carbon concentration in snow, Atmos. Meas. Tech., 5, 2581-2592, https://doi.org/10.5194/amt-5-2581-2012, 2012.
Simpson, W. R., King, M. D., Beine, H. J., Honrath, R. E., and Zhou, X.: Radiation-transfer modeling of snow-pack photochemical processes during ALERT 2000, Atmos. Environ., 36, 26632670, 2002.

Skiles, S. M.: Dust and black carbon radiative forcing controls on snowmelt in the Colorado River Basin, PhD thesis, Geography, University of California, Los Angeles, USA, 2014.

Skiles, S. M., Flanner, M., Cook, J. M., Dumont, M., and Painter, T. H.: Radiative forcing by light-absorbing particles in snow, Nat. Clim. Change, 8, 964-971, 2018.

Tuzet, F., Dumont, M., Lafaysse, M., Picard, G., Arnaud, L., Voisin, D., Lejeune, Y., Charrois, L., Nabat, P., and Morin, S.: A multilayer physically based snowpack model simulating direct and indirect radiative impacts of light-absorbing impurities in snow, The Cryosphere, 11, 2633-2653, https://doi.org/10.5194/tc-112633-2017, 2017.

Voisin, D., Jaffrezo, J.-L., Houdier, S., Barret, M., Cozic, J., King, M., France, J., Reay, H., Grannas, A., Kos, G., and Ariya, P.: Carbonaceous species and HUmic LIke Substances (HULIS) in Arctic snowpack during OASIS field campaign in Barrow, J. Geophys. Res., 117, D00R19, https://doi.org/10.1029/2011JD016612, 2012.

Wang, X., Wei, H., Liu, J., Xu, B., Wang, M., Ji, M., and Jin, H.: Quantifying the light absorption and source attribution of insoluble light-absorbing particles on Tibetan Plateau glaciers between 2013 and 2015, The Cryosphere, 13, 309-324, https://doi.org/10.5194/tc-13-309-2019, 2019.

Warren, S.: Optical properties of snow, Rev. Geophys., 20, 67-89, https://doi.org/10.1029/RG020i001p00067, 1982.

Warren, S. and Brandt, R.: Optical constants of ice from the ultraviolet to the microwave: A revised compilation, J. Geophys. Res., 113, D14220, https://doi.org/10.1029/2007JD009744, 2008.

Warren, S. G.: Can black carbon in snow be detected by remote sensing?, J. Geophys. Res.-Atmos., 118, 779-786, https://doi.org/10.1029/2012JD018476, 2013.

Warren, S. G., Brandt, R. E., and Grenfell, T. C.: Visible and nearultraviolet absorption spectrum of ice from transmission of solar radiation into snow, Appl. Optics, 45, 5320-5334, 2006.

Wendl, I. A., Menking, J. A., Färber, R., Gysel, M., Kaspari, S. D., Laborde, M. J. G., and Schwikowski, M.: Optimized method for black carbon analysis in ice and snow using the Single Particle Soot Photometer, Atmos. Meas. Tech., 7, $2667-$ 2681,https://doi.org/10.5194/amt-7-2667-2014, 2014.

Wiscombe, W. J. and Warren, S. G.: A model for the spectral albedo of snow. I: Pure snow, J. Atmos. Sci., 37, 2712-2733, 1980. 